\title{
Carbon dioxide anion radical as a tool to enhance lignin valorization
}

Mazarji, Mahmoud; Kuthiala, Sidhant; Tsapekos, Panagiotis; Alvarado-Morales, Merlin; Angelidaki, Irini

\section{Published in:}

Science of the Total Environment

Link to article, DOI:

10.1016/j.scitotenv.2019.05.102

Publication date:

2019

Document Version

Peer reviewed version

Link back to DTU Orbit

Citation (APA):

Mazarii, M., Kuthiala, S., Tsapekos, P., Alvarado-Morales, M., \& Angelidaki, I. (2019). Carbon dioxide anion radical as a tool to enhance lignin valorization. Science of the Total Environment, 682, 47-58.

https://doi.org/10.1016/j.scitotenv.2019.05.102

\section{General rights}

Copyright and moral rights for the publications made accessible in the public portal are retained by the authors and/or other copyright owners and it is a condition of accessing publications that users recognise and abide by the legal requirements associated with these rights.

- Users may download and print one copy of any publication from the public portal for the purpose of private study or research.

- You may not further distribute the material or use it for any profit-making activity or commercial gain

- You may freely distribute the URL identifying the publication in the public portal 


\section{Carbon dioxide anion radical as a tool to enhance lignin valorization}

2 Mahmoud Mazarji ${ }^{\mathrm{a}, \mathrm{b}}$, Sidhant Kuthiala ${ }^{\mathrm{a}}$, Panagiotis Tsapekos ${ }^{\mathrm{a}}$, Merlin Alvarado-Morales ${ }^{\mathrm{a}}$,

${ }^{a}$ Department of Environmental Engineering, Technical University of Denmark, Kgs. Lyngby, DK-2800,

${ }^{\mathrm{b} S c h o o l ~ o f ~ E n v i r o n m e n t, ~ C o l l e g e ~ o f ~ E n g i n e e r i n g, ~ U n i v e r s i t y ~ o f ~ T e h r a n, ~ T e h r a n, ~ I r a n ~}$

\section{Abstract}

Lignin is particularly recalcitrant for valorization via the existing pretreatment methods due to its complex cross-linking polymeric network. The aim of this study is to develop a novel integrated pretreatment strategy to exploit the potential of lignocellulosic biomass as resource for production of biofuels and aromatic chemicals. In this regard, a novel $\mathrm{UV} / \mathrm{TiO}_{2} / \mathrm{HCOOH}$ reaction was proposed to systematically generate hydroxyl radical $\left({ }^{\bullet} \mathrm{OH}\right)$ and carbon dioxide radical anion $\left(\mathrm{CO}_{2}{ }^{\bullet-}\right)$ to depolymerize lignin. Usage of 2,3dihydrobenzofuran as a simple probe molecule showed cleavage $\beta$-O-4 linkage occurred via $\mathrm{H}$ abstraction mechanism. The addition of methyl viologen as $\mathrm{CO}_{2}{ }^{\bullet-}$ scavengers proved the presence of $\mathrm{CO}_{2}{ }^{\bullet-}$ in this $\mathrm{UV} / \mathrm{TiO}_{2} / \mathrm{HCOOH}$ reaction. Lignin and wheat straw were used to investigate the effect of different parameters, including formic acid concentration and $\mathrm{TiO}_{2}$ dosage, on the efficiency of the reaction. At optimized conditions, the highest phenolic concentrations attained were 173.431 and $66.802 \mathrm{mg} / \mathrm{g}$ lignin and wheat straw, respectively. A cycle test was designed with the aim to favor the complete consumption of formic acid through more pretreatment cycles for producing the highest possible Total Phenolic Compounds (TPC) in the liquid phase. After the third consecutive cycle, $103.651 \pm 5.964 \mathrm{mg}-\mathrm{TPC} / \mathrm{g}$, was obtained. Meanwhile it was found the remaining wheat straw solid fibers used for biogas production, showed 11.0\% increase biogas production and increased degradation rate compared to the untreated wheat straw. Keywords: lignin oxidation; lignocellulosic biomass; pretreatment; carbon dioxide radical anion; high-value products 


\section{Introduction}

Biomass is attracting increased interest due to its potential as an inexpensive, sustainable, and renewable carbon source for partial substitution of fossil resources (Menon and Rao, 2012). Current research is focused on utilizing lignocellulosic biomass within a circular economy framework for the production of energy, valuable chemicals, materials, and fuels. Lignocellulose is the major structural component of woody and non-woody plants consisted of cellulose, hemicellulose, and lignin. While technologies to process cellulose and hemicellulose are well developed, lignin processing constitutes a considerably more challenging task (Kärkäs et al., 2016). Lignin, which constitutes 10-25 wt\% of lignocellulosic biomass, is the only renewable source of aromatic hydrocarbons in the biosphere exceeding 300 billion tons (Smolarski, 2012). Lignin consists of three phenyl propane units, namely, p-coumaryl, coniferyl, and sinapyl alcohols connected by ether and carbon-carbon bonds such as $\beta$-aryl ether ( $\beta$-O-4), $\alpha$-aryl ether $(\alpha-\mathrm{O}-4)$, diphenyl ether (4-O-5), and biphenyl (5-5) in a bulky and highly functionalised fashions (Pérez et al., 2002). If efficiently depolymerized, a pallet of value-added renewable chemicals (i.e. phenols, aromatic, and aliphatic compounds) can be produced to replace fossil fuel based products. However, it is difficult to depolymerize lignin into various products because of its highly cross-linking and random structure (Wang et al., 2018). Due to the high thermal and chemical stability of $\mathrm{C}-\mathrm{C}$ and $\mathrm{C}-\mathrm{O}$ bonds, lignin is resistant to traditional physical, chemical, and biological degradation (Brodeur et al., 2011; Pineda and Lee, 2016). Considering this, several research groups are investigating different pretreatment methods to target cleaving abundance of $\beta-O-4$ or biphenyl-type (5-5) linkages to produce different possible compounds (Pineda and Lee, 2016). Many methods have been proposed to realize more efficient lignin oxidative depolymerization strategies, while effective conversion to stable products is still a big challenge due to uncontrollable overoxidation of substrate to gaseous products (Sun et al., 2018).

Different strategies have been developed in order to i) generate valuable aromatic chemicals and/or provide a source of low-molecular-mass feedstocks suitable for downstream processing and ii) increase biomass biodegradability for bioenergy production. In this regard, advanced oxidation process associated with a generation of highly reactive hydroxyl radical $\left({ }^{\bullet} \mathrm{OH}\right)$ received remarkable attention due to its ability to target 
51 a wide variety of refractory organic pollutants. These pollutants including persistent organic pollutants 52 (POPs) (Dong et al., 2015) and synthetic dyes (Rauf and Ashraf, 2009) are difficult to eliminate from liquid

effluents with conventional methods due to their recalcitrant features. Photocatalysis, among these strategies, involves generation of highly reactive radicals namely ${ }^{\bullet} \mathrm{OH}$ and superoxide anion radical $\left(\mathrm{O}_{2}^{\bullet}\right)$ under controlled operation. Unlike other pretreatments which demand severe conditions (high temperature and pressure), this pretreatment can be carried out efficiently under mild conditions to produce highly valuable phenolic or other low molecular weight compounds.

The main drawback of a typical photocatalysis is an uncontrolled oxidation resulting in a complete mineralization of the organic matter (Alvarado-Morales et al., 2017; Nair et al., 2016). Some reports indicated that ${ }^{\bullet} \mathrm{OH}$ is involved in the photocatalytic degradation of lignin ( $\mathrm{Li}$ et al., 2015; Machado et al., 2000), while others showed that $\mathrm{O}_{2}{ }^{\bullet-}$ plays the main role in this field (Chen et al., 2018; Gong et al., 2017). The advantages of using the ${ }^{\bullet} \mathrm{OH}$ contra $\mathrm{O}_{2}{ }^{\bullet}$ for lignin depolymerization is because its redox potential is higher $\left(2.80 \mathrm{~V}, v s\right.$. standard hydrogen electrode (SHE)) compared to redox potential of $\mathrm{O}_{2}{ }^{\bullet-}(0.890 \mathrm{~V}, v s$. SHE). However, ${ }^{\bullet} \mathrm{OH}$ is considered as a highly non-selective radical which often results in a complete decomposition of compounds in the reaction medium (Gong et al., 2017). Moreover, the production of $\mathrm{O}_{2}{ }^{\bullet}$ during the photocatalytic reaction is not controllable, since it can easily transform to hydroperoxyl radical with a less redox potential. These reasons highlight the significance of introducing a new radical type in the field of lignin oxidation.

Carbon dioxide anion radical $\left(\mathrm{CO}_{2}{ }^{--}\right)$is a very strong one-electron oxidant acting both as electron transfer and $\mathrm{H}$ abstraction mechanism (Rosso et al., 2001) and has recently received considerable attention for remediation chlorinated hydrocarbons and chromium contamination (Gu et al., 2017; Ren et al., 2017). In most cases, various methods, including vacuum ultraviolet (UV) irradiation (i.e. $175 \mathrm{~nm}$ ) of aqueous solutions containing formate at $\mathrm{pH} 4$ (Rosso et al., 2001), $\Upsilon$ radiolysis of water (and water solutions) in air (Todres, 2009), thermally activated persulfate system $\left(50^{\circ} \mathrm{C}\right)$ in the presence of formate anions (Ren et al., 2017), and activation of formic acid and sulfate radical produced under $\mathrm{UV} / \mathrm{S}_{2} \mathrm{O}_{8}{ }^{2-}$ process (Gu et al., 2017) are applied to generate $\mathrm{CO}_{2}{ }^{\bullet-} \cdot \mathrm{CO}_{2}{ }^{\bullet-}$ is characterized by better electron transfer and $\mathrm{H}$ abstraction 
mechanisms -compared to $\mathrm{O}_{2}^{\bullet-}$ (Rosso et al., 2001). It is well known that pure lignin and lignin richbiomasses contain $\beta$-O-4 linkages as the weakest available bond, so the cleavage of $\mathrm{C}_{\text {aryl}}-\mathrm{O}$ bonds in lignin is a facile alternative approach for lignin depolymerization (Zhang et al., 2016). The reaction of $\mathrm{CO}_{2}{ }^{\bullet-}$ with $\beta$ O-4 linkages in lignin would lead to the formation phenolic monomers.

The present study examines a novel advanced oxidation route using $\mathrm{UV} / \mathrm{TiO}_{2} / \mathrm{HCOOH}$ for depolymerization of lignin into phenolic compounds by generation of newly $\mathrm{CO}_{2}{ }^{--}$alongside powerfully ${ }^{\bullet} \mathrm{OH}$ at a very mild conditions. Taking into account the pure lignin and lignin rich-biomasses contain $\beta-O-4$ linkages as the weakest available bond, so the cleavage of $\mathrm{C}_{\text {aryl- }} \mathrm{O}$ bonds by $\mathrm{H}$ abstraction would present a simple and facile alternative approach for lignin depolymerization. Production of $\mathrm{CO}_{2}{ }^{\bullet-}$ and $\bullet$ OH for cleavage of the $\beta-\mathrm{O}-4$ linkage, initially was tested against 2,3-dihydrobenzofuran as a simple probe molecule. Then, the existence of $\mathrm{CO}_{2}{ }^{\bullet-}$ in the system was examined by using methyl viologen. After detailed mechanism analysis, the proposed process was adopted to test the applicability of the pretreatment method for the production of highvalue products from lignin and wheat straw as an actual lignocellulosic biomass. In addition, the pretreated materials were anaerobically digested to evaluate the suitability of the photocatalytic solution for energy recovery purposes.

\section{Materials and methods}

\subsection{Materials}

Sigma-Aldrich Kraft lignin (product number 370959), abbreviated as lignin and formic acid (analytical grade, ACS reagent, $\geq 98 \%$ ) were purchased from Sigma-Aldrich while gases were provided by AGA A/S (Copenhagen, Denmark). Photocatalyst grade Titanium (IV) Oxide $\left(\mathrm{TiO}_{2}\right)$ (product number 248576) composed of anatase and $\sim 5 \%$ rutile in a powder form -325 mesh, $\geq 99 \%$ trace metal basis was obtained from Sigma-Aldrich. Wheat straw residues were collected from the surrounding area of Copenhagen (Zealand, Denmark) and cut to less than $0.50 \mathrm{~cm}$ length by a cutting mill machine (SM 200, Retsch GmbH, Germany). Subsequently, the resulting fibers were sieved using $1 \mathrm{~mm}$ sieve (size $18 \mathrm{mesh}$ ) to obtain a homogeneous particle size. The total solids (TS) and volatile solids (VS) of the wheat straw were $92.80 \pm$ 
$0.40 \%$ and $86.70 \pm 0.10 \%$ of fresh matter. The more detailed characterizations can be found elsewhere (Alvarado-Morales et al., 2017).

\subsection{Experimental procedure}

Photocatalytic batch experiments were conducted in a quasi-collimated beam apparatus. A doped medium pressure lamp (SR HUV700 (European patent: EP1463091A2), 700 W, Scan Research A/S, Denmark) was used inside the reactor setup with a specific feature of enhancing emission at low wavelength. Detailed characteristics of the lamp and reactor setup were described previously (Hansen et al., 2013). Prior to the experiments, preparation started with overnight soaking samples including lignin and wheat straw in an appropriate volume of formic acid $(98-100 \mathrm{w} / \mathrm{w} \%)$ solution. After $24 \mathrm{~h}$ soaking of the samples, distilled water was added to the solution to obtain the desired concentration of formic acid at $100 \mathrm{~mL}$ solution. Equilibration period at dark was initiated with addition of the desired amount of $\mathrm{TiO}_{2}$ into the resulting solution in order to establish an adsorption-desorption equilibrium among the photocatalyst surface and sample's molecules. After 60 min of adsorption, the UV lamp was turned on, followed by air sparging. Aquarium air pump with flow rate of $1.5 \mathrm{~L} / \mathrm{min}$ was used to assure the availability of sufficient amount of oxygen and removal of other gasses generated during the reaction from the reactor. At given intervals of illumination, the samples of reaction solution were collected and centrifuged for $10 \mathrm{~min}$ at $13000 \mathrm{rpm}$. The supernatant was collected for determination of total phenolic compounds (TPC) \% change and soluble chemical oxygen demand (sCOD) \% change. The solid residues were collected by passing the solution through a Whatman ${ }^{\circledR} 41$ (125 mm diameter) filter paper. After recovering of solid residues by the filter paper, the leftover was dried completely in an oven at $60{ }^{\circ} \mathrm{C}$ for further experiments and characterizations.

\subsection{Experimental design}

The experiment was built according to the response surface methodology (RSM) for two independent variables namely formic acid concentration $\left(\mathrm{x}_{1}\right)$ and $\mathrm{TiO}_{2}$ dosage $\left(\mathrm{x}_{2}\right)$. The design chosen for the study was a faced central composite design (fCCD), where the independent variables were investigated at three levels of $(-1,0,+1)$. Preliminary experiments were conducted to determine a narrower range of independent variables 
prior to designing the experimental runs. For this purpose, experiments were carried out by varying a single

128 factor while keeping all other factors fixed at a specific set of conditions. It should be noted that due to the results of preliminary experiments, the experimental ranges for formic acid concentration and $\mathrm{TiO}_{2}$ dosage were not similar for lignin and wheat straw sample. According to the obtained experimental data, the ranges of independent variables and experimental derived from fCCD are given in Table 1.

For statistical calculations and model developments, the real values of the independent variables $\left(\mathrm{X}_{\mathrm{i}}\right)$ were converted to dimensionless coded values between +1 and $-1\left(\mathrm{x}_{\mathrm{i}}\right)$ according to Eq. (1):

$x_{i}=\frac{X_{i}-X_{0}}{\delta X}$

where $\mathrm{X}_{0}$ and $\delta \mathrm{X}$ are the real value of $\mathrm{X}_{\mathrm{i}}$ at the center point and the step change, respectively.

In total, 10 experiments for each case, comprising of 4 factorial points, 4 axial points, and 2 replications at the center points were performed for allowing the estimation of experimental error. Table 2 provides the details of the 10 experimental conditions planned for each experiment.

Experimental data were analyzed using statistical analysis software JMP Pro 13 (SAS Institute Inc.) and fitted to a second-order polynomial model to optimize the variables in the oxidation process. The quadratic equation model for predicting the optimal conditions as a function of the two independent variables can be expressed as Eq. (2):

$Y=\beta_{0}+\sum_{i=1}^{n} \beta_{i} x_{i}+\sum_{i=1}^{n} \beta_{i i} x_{i}^{2}+\sum_{i=1}^{n} \sum_{j=i+1}^{n} \beta_{i j} x_{i} x_{j}$

where, $Y(\%)$ represents the predicted response; $x_{i}$ and $x_{j}$ are the coded $i$ and $j^{\text {th }}$ independent coded variable; $\beta_{0}, \beta_{i}, \beta_{i i}$, and $\beta_{i j}$ are the intercept, the first-order model coefficient, the quadratic coefficient of variable $i$, and the interaction coefficient of variables $i$ and $j$, respectively. The reliability of the fitted model was evaluated based on the analysis of variance (ANOVA) and as well as the coefficient of determination $\left(\mathrm{R}^{2}\right)$.

After developing the second-order polynomial model, the optimal values of the parameters were achieved by analyzing the surface and counter plots by solving the obtained regression equations. For the lignin sample, the goal was set to maximize the TPC $\%$ change. For wheat straw, the optimization was focused on 
maximum TPC $\%$ change and minimum sCOD $\%$ change. This is explained as: i) high-value products are obtained in the liquid phase by high TPC, ii) less solubilization of wheat straw fibers is achieved into the solution (i.e. the treated wheat straw can be used for biogas production, hence sCOD amount in solution is to 152 be limited).

\subsection{Mechanism study by probe molecule and radical scavenger}

In order to investigate the underlying mechanism behind the oxidation process of lignin, 2,3dihydrobenzofuran as a simple probe molecule was used. At the optimal conditions achieved for lignin, the reaction was carried out in a $100 \mathrm{~mL}$ solution containing $0.2 \mathrm{~g} / \mathrm{L}$ of 2,3-dihydrobenzofuran, $0.1 \mathrm{~g} / \mathrm{L} \mathrm{TiO}_{2}$, and $0.25 \mathrm{M}$ formic acid. Then, the reaction solution was aerated under vigorous stirring. At specific times samples were collected. Before storage, the samples were firstly centrifuged for $10 \mathrm{~min}$ at $13000 \mathrm{rpm}$ and then, the recovered supernatant was filtered by a $0.45 \mu \mathrm{m}$ filter (Agilent $\left.{ }^{\circledR}\right)$. The control experiment without formic acid was also conducted at same conditions to study the effect of photocatalytic oxidation of $\mathrm{TiO}_{2}$. To prove the $\mathrm{CO}_{2}{ }^{\bullet-}$ formation responsible for the oxidation of lignin, methyl viologen dichloride $\left(\mathrm{MV}^{2+}, 98 \%\right.$, Sigma-Aldrich) was introduced to the system. This method was similar to the above method of photocatalytic activity test except addition of 0.10 and $0.01 \mathrm{mM}$ scavenger in the presence of lignin according to the method presented by (Ren et al., 2017).

\subsection{Cycling test and biochemical methane potential (BMP) assays}

After selection of optimized conditions, the cycle test was designed to achieve the highest concentration of value added chemicals (i.e. phenolics) in the liquid phase. At the end of each cycle wheat straw fibers were separated from the solution. In this regard, the first cycle (denoted as $1^{\text {st }}$ cycle) was run for $240 \mathrm{~min}$ after which the solution was passed through filter paper to separate the solid and liquid phase. The liquid phase was then reused for the second and third cycle adding always fresh $1 \mathrm{~g} / \mathrm{L}$ wheat straw. The final collected treated wheat straw after production of phenolics was dried in an oven at $60{ }^{\circ} \mathrm{C}$ for 24 hours and was used for the methane production. 
BioMethane potential (BMP) assay was performed to determine biodegradability and methane production

174 potential of the pretreated sample after $1^{\text {st }}, 2^{\text {nd }}$ cycle, and untreated wheat straw. Samples were prepared 175 according to the guidelines of Angelidaki et al (Angelidaki et al., 2011). All samples were prepared in triplicate in $337 \mathrm{~mL}$ glass bottles at an organic load of $1.50 \mathrm{gVS} / \mathrm{L}$. Avicel (PH-101, Sigma Aldrich) was used as the control at the same organic load. Blank bottles containing inoculum and water were also prepared to define the background methanation from the inoculum. The inoculum was obtained from the effluent of a well-performing lab-scale biogas reactor fed with source separated municipal organic waste. Before usage, the inoculum was placed in a thermophilic incubator $\left(55 \pm 1^{\circ} \mathrm{C}\right)$ to be degassed for 7 days to eliminate the background methane production. During the incubation period, the reactors were shaken once a day to avoid the development of dead zones. The methane concentration in the headspace of batch reactors was determined using a gas chromatograph (Thermo Scientific ${ }^{\mathrm{TM}}$, Trace ${ }^{\mathrm{TM}} 1310$ ) as previously described (Khoshnevisan et al., 2018). For the degradability experiments, the methane yields were reported at standard temperature and pressure (STP) conditions. The experiments were conducted at thermophilic conditions $186\left(54 \pm 1^{\circ} \mathrm{C}\right)$.

\subsection{Analytical methods and calculations}

\subsubsection{Characterization of aqueous phase products}

The production of phenolics was probed on a spectrophotometer (UV-vis spectrophotometer UH5300 Hitachi) over the wavelength ranges of 250 to $400 \mathrm{~nm}$. The concentration of total phenolic compound (TPC) was determined based on the Folin-Ciocalteu method (Ainsworth and Gillespie, 2007). A characteristic peak at $725 \mathrm{~nm}$ reveals the TPC content after the reaction with the Folin-Ciocalteu reagent and sodium carbonate. A calibration curve for each measurement was done using gallic acid as standard and subsequently, a calibration plot was constructed to quantify the TPC content. TPC was expressed as mg phenolics produced per $\mathrm{g}$ of lignin used $(\mathrm{mg} / \mathrm{g})$ depending on the lignin content of the substrate. TPC was calculated using the equation as follows:

$T P C=\frac{[C] \times[V]}{[M] \times[\text { Lignin content }]}$ 
where $\mathrm{M}, \mathrm{V}$, and $\mathrm{C}$ are loading of wheat straw or lignin $(\mathrm{g} / \mathrm{L})$, volume of solution $(\mathrm{L})$, and quantified concentration of phenolics from calibration curve $(\mathrm{mg} / \mathrm{L})$, respectively. The lignin content value was $26.70 \pm$ $2.40 \% \mathrm{TS}$ and $100 \%$ for wheat straw and lignin sample, respectively (Tsapekos et al., 2017).

COD was determined according to the Standard Methods (APHA, 1998). For the soluble COD (sCOD), the samples were centrifuged and only the supernatant was used. TPC or SCOD (\%) change was determined using the following equation:

$Y(\%)$ change $=\left[\frac{\left(C_{t}-C_{0}\right)}{C_{0}}\right] \times 100$

where $\mathrm{C}_{\mathrm{t}}$ and $\mathrm{C}_{0}$ are the concentration of TPC $(\mathrm{mg} / \mathrm{g})$ or $\mathrm{sCOD}(\mathrm{mg} / \mathrm{L})$ at time $(\mathrm{t})$ and initial time, respectively.

Analysis of the molecules in the liquid phase produced after the process was conducted with a gas chromatography/Mass spectrometry (GC/MS, Agilent 7890A/ 5975C). The analysis conditions were chosen as follow: a capillary column was used (HP-INNOWAX, $30 \mathrm{~m} \times 0.25 \mathrm{~mm} \times 0.25 \mu \mathrm{m}$ ) at programmed oven temperature of $60{ }^{\circ} \mathrm{C}$, hold for 2 minutes at $60{ }^{\circ} \mathrm{C}$ and then ramped up at a rate of $10{ }^{\circ} \mathrm{C} /$ minute to $260{ }^{\circ} \mathrm{C}$ and hold at this level for extra 10 minutes; the injector was kept at $280{ }^{\circ} \mathrm{C}$ in spit mode with spit ratio of 1:10 and splitless; helium was used as the carrier gas. The listed compounds were identified by comparing with National Institute of Standards and Technology (NIST) mass spectral database.

Formate and formic acid were detected and quantified using high performance liquid chromatography, HPLC. The HPLC (Agilent) had a refractive index detector (detection of sugars, VFAs and ethanol) and a Bio-Rad Aminex HPX-87H column $(300 \mathrm{~mm} \times 7.8 \mathrm{~mm})$ with $0.04 \mathrm{M} \mathrm{H}_{2} \mathrm{SO}_{4}$ as eluent and flow rate was set to $0.6 \mathrm{~mL} \mathrm{~min}{ }^{-1}$ with column oven temperature set to $63.5^{\circ} \mathrm{C}$.

\subsubsection{Characterization of solid phase fibers}

The element measurement of non-volatile product was carried out on an elemental analyzer (Elementar vario MACRO cube). Crystallinity of the wheat straw samples was determined by X-ray diffraction (XRD) using a 

estimated based on the following equation described by (Segal et al., 1959):

$\operatorname{CI}(\%)=\left[\frac{\left(I_{002}-I_{18}\right)}{I_{002}}\right] \times 100$

221 where $I_{002}$ is the intensity of the diffraction at 002 peak position $\left(2 \theta \approx 22.5^{\circ}\right)$ for cellulose and $I_{18}$ is the peak 222 for the amorphous region at about $2 \theta \approx 18^{\circ}$.

223 The functional groups were measured by Fourier transform infrared spectroscopy (FTIR) using a Spectrum 224 One spectrophotometer (Nicolet iS50, Thermo Fisher Scientific). The total crystallinity Index (TCI) was 225 calculated according to the method of Nelson and O'Connor (Nelson and O'Connor, 1964), i.e. ratio between 226 the peaks at 1372 and $2920 \mathrm{~cm}^{-1}$ from FTIR spectra. Scanning electron microscopy (SEM) analysis was 227 performed with an FEI Quanta 200 ESEM FEG without any coating to study morphological change for the treated wheat straw after the process. For a separation of the pretreated solid fibers, a glass microfiber filter (Whatman GF/C 47Ø) was used. The treated and untreated wheat straw samples were dried in an oven at 100 ${ }^{\circ} \mathrm{C}$ for 24 hours prior to characterization.

\subsubsection{Statistical analysis}

One-way analysis of variance (ANOVA) followed by Fisher's Least Significant Difference test (LSD, $p<$ 0.05) was conducted to verify the existence of a statistically significant difference among experimental measurements. All statistical analyses were performed using OriginPro 9.0.0 SR2 software (OriginLab 235 Corporation, USA).

\section{Results and discussion}

\subsection{Mechanism analysis}

\section{3.1.1. Mechanism formulation and proposed reaction pathway}

239 The used lamp is capable of homolysis of water since it can irradiate the wavelength in the range of 150 to $200 \mathrm{~nm}$ (Zoschke et al., 2014), and water molecule can be converted to ${ }^{\bullet} \mathrm{O} \mathrm{OH}$ and $\mathrm{H}$ atom $\left(\mathrm{H}^{\bullet}\right)$. Then, ${ }^{\bullet} \mathrm{OH}$ and $\mathrm{H}^{\bullet}$ can react with formate or formic acid to produce $\mathrm{CO}_{2}{ }^{\bullet}$ (Rosso et al., 2001). This mechanism of 
$242 \mathrm{CO}_{2}{ }^{\bullet-}$ production can be expressed as the chain of reactions through the multistep continuous reactions (Eqs.

$243(6)-(10))$

$\mathrm{H}_{2} \mathrm{O} \stackrel{150<h v<200}{\longrightarrow} \mathrm{OH}+\mathrm{H}^{\bullet}$

$\bullet \mathrm{OH}+\mathrm{HCO}_{2}^{-} \rightarrow \mathrm{H}_{2} \mathrm{O}+\mathrm{CO}_{2}^{\bullet-}$

$\bullet \mathrm{OH}+\mathrm{HCO}_{2} \mathrm{H} \rightarrow \mathrm{H}_{2} \mathrm{O}+\mathrm{HCO}_{2}^{\bullet}$

$\mathrm{H}^{\bullet}+\mathrm{HCO}_{2}^{-} \rightarrow \mathrm{H}_{2}+\mathrm{CO}_{2}^{\bullet-}$

$\mathrm{H}^{\bullet}+\mathrm{HCO}_{2} \mathrm{H} \rightarrow \mathrm{H}_{2}+\mathrm{HCO}_{2}^{\bullet}$

244 The presence of $\mathrm{TiO}_{2}$ can promote the production of ${ }^{\bullet} \mathrm{OH}$ in the solution. The following mechanism is 245 proposed for $\mathrm{UV} / \mathrm{TiO}_{2}$ system. The photoinduced electrons and holes were generated upon excitation of $246 \mathrm{TiO}_{2}$, as described in Eq. (11). These separated electrons would subsequently eject on the surface of $\mathrm{TiO}_{2}$, ready for quenching by $\mathrm{O}_{2}$ to form $\mathrm{O}_{2}{ }^{\bullet-}$ by Eq. (12). Furthermore, ${ }^{\bullet} \mathrm{OH}$ would generate from oxidation of hydroxyl anion at the holes (Eq. (13)).

$\mathrm{TiO}_{2}+h v \rightarrow e^{-}+h^{+}$

$e^{-}\left(\mathrm{TiO}_{2}\right)+\mathrm{O}_{2} \rightarrow \mathrm{O}_{2}^{\bullet-}$

$h^{+}\left(\mathrm{TiO}_{2}\right)+\mathrm{OH}^{-} \rightarrow{ }^{\bullet} \mathrm{OH}$

249 The combination of photocatalysis (the direct formation of ${ }^{\bullet} \mathrm{OH}$ and $\mathrm{O}_{2}{ }^{\bullet-}$ ) and photolysis process (the direct

250 formation $\mathrm{CO}_{2}{ }^{\bullet-}$ ) can establish advanced oxidation conditions comparable to other traditional advanced 251 oxidation processes (AOPs).

252 An initial understanding of the reaction mechanisms was attempted by using a simple molecule having $\beta-\mathrm{O}-4$ 253 linkage, similar to the lignin molecule. Specifically, 2,3-dihydrobenzofuran was used as a probe molecule 254 (i.e. representative of $\beta$-O-4 linkage inside the lignin) in order to elucidate the oxidation mechanism of $\mathrm{CO}_{2}{ }^{\bullet-}$ 255 and $\bullet \mathrm{OH}$. The obtained reaction products were determined by GC/MS and a brief reaction pathway of 2,3256 dihydrobenzofuran oxidation in the presence of formic acid and/or $\mathrm{TiO}_{2}$ was proposed. As shown in Fig. 1, 257 after $30 \mathrm{~min}, 2,3$-dihydrobenzofuran converted to benzofuran and 2-methoxybenzaldehyde with approximate 258 conversion of $39.0 \%$ and $67.0 \%$, respectively. With the extension of reaction time, the selectivity of 259 benzofuran decreased, vice versa the selectivity of 2-methoxybenzaldehyde increased. Hence, it can be 
concluded that the reaction driven by $\mathrm{CO}_{2}{ }^{\bullet-}$ led to the selective attack of $\beta$-O-4 linkage via $\mathrm{H}$ abstraction from aromatic ring of 2,3-dihydrobenzofuran (to form benzofuran), as well as a competing pathway involved oxygen addition to carbon-centered radical, elimination to form aldehyde accompanying with cleavage of furan ring, which ultimately resulted in the production of 2-methoxybenzaldehyde.

Furthermore, the presence of $\mathrm{TiO}_{2}$ would catalyze this step to produce more of $\mathrm{CO}_{2}{ }^{\bullet-}$ (Eqs. (7) and (8)), besides the eventual production of ${ }^{\bullet} \mathrm{OH}$. An analogues experiment was also conducted in the presence of only formic acid, and the similar results were obtained with lower conversion yield. This implies the necessity of using $\mathrm{TiO}_{2}$ for enhancement of overall conversion yield. However, it should be mentioned during oxidation of the probe molecule at the presence of only $\mathrm{TiO}_{2}$, the formation of ${ }^{\bullet} \mathrm{OH}$ and $\mathrm{O}_{2}{ }^{\bullet-}$ led to the unselective direct degradation of the probe molecule (data not shown).

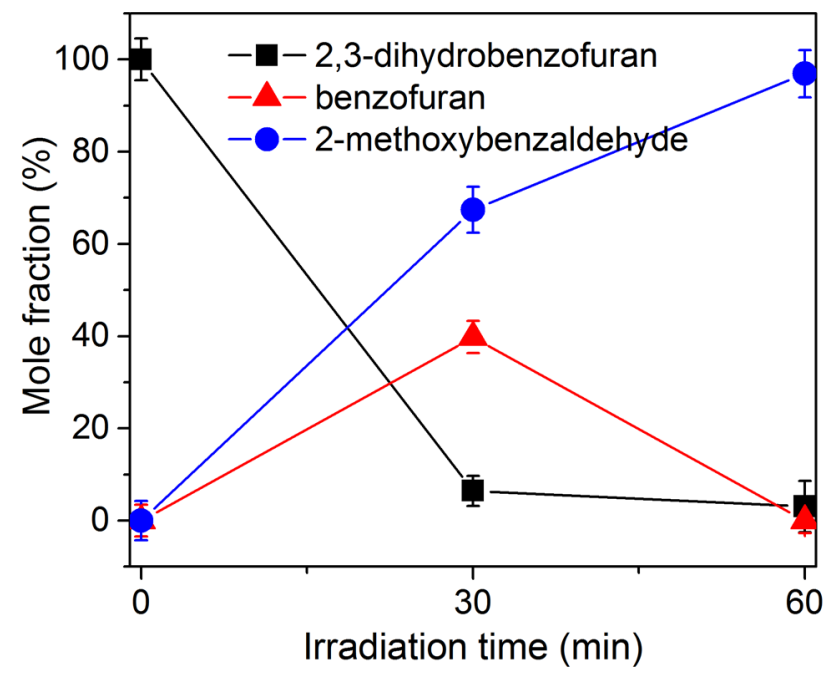

Fig. 1. Mole fraction profiles of 2,3-dihydrobenzofuran oxidation and its obtained products as a function of time. Conditions: 2,3-dihydrobenzofuran loading $0.2 \mathrm{~g} / \mathrm{L}$; formic acid concentration $0.25 \mathrm{M} ; \mathrm{TiO}_{2}$ dosage 0.1 $\mathrm{g} / \mathrm{L}$; final volume $100 \mathrm{~mL}$; saturated with air.

\subsubsection{Radical identification}

Mainly electron spin resonance (ESR) and radical scavenger experiments are employed for identification of $\mathrm{CO}_{2}{ }^{\bullet-}$. In this context, using ESR experiment to verify the presence $\mathrm{CO}_{2}{ }^{\bullet-}$ and $\mathrm{SO}_{4}{ }^{\bullet-}$ was reported by (Ren et al., 2017). In addition, methyl viologen $\left(\mathrm{MV}^{2+}\right)$ has been widely used in the literature (Berkovic et al., 2012, 
2010; Gu et al., 2017), as a competitive scavenger to react with $\mathrm{CO}_{2}{ }^{\bullet-}$. Hence, this method was employed to

279 identify the existence of $\mathrm{CO}_{2}{ }^{\bullet-}$. Fig. 2 shows the inhibitory effect of this scavenger relatively to control

280 experiment ran at the center point conditions for lignin. It can be seen from Fig. 2 that TPC concentration in 281 the absence of $\mathrm{MV}^{2+}$ increased to $164.112 \pm 0.991 \mathrm{mg} / \mathrm{g}$ after $180 \mathrm{~min}$. TPC production in the presence of 2820.01 and $0.10 \mathrm{mM} \mathrm{MV}^{2+}$ were decreased to $130.330 \pm 1.164$ and $120.512 \pm 1.092 \mathrm{mg} / \mathrm{g}$, respectively. The 283 results showed that the reaction was quenched with the addition of $\mathrm{CO}_{2}{ }^{\bullet-}$ scavenger as described by Eq. (14). 284 Therefore, $\mathrm{CO}_{2}{ }^{\circ-}$ as the predominant active species is responsible for the TPC production in the $285 \mathrm{UV} / \mathrm{TiO}_{2} / \mathrm{HCOOH}$ reaction.

$\mathrm{CO}_{2}^{\bullet-}+\mathrm{MV}^{2+} \rightarrow \mathrm{MV}^{\bullet+}+\mathrm{CO}_{2}$

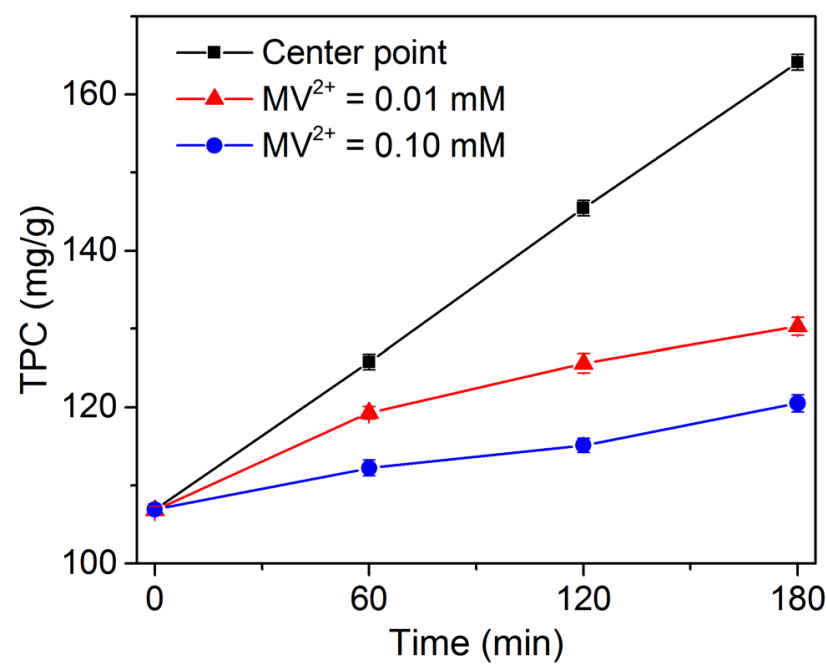

Fig. 2. TPC concentration $(\mathrm{mg} / \mathrm{g})$ as a function of time with the addition of different methyl viologen $\left(\mathrm{MV}^{2+}\right)$ concentration at center point (experiments 6-7). Fixed experimental conditions: lignin loading $0.2 \mathrm{~g} / \mathrm{L}$; final volume $100 \mathrm{~mL}$; saturated with air.

\subsection{Effect of parameters on TPC results of lignin and wheat straw}

291 The results from the first optimization step (fCCD) are presented in Fig. 3. The yield in terms of TPC for each experimental run is also reported in Table 2. For the simplicity of explanation, the experiments were divided into three categories based on the level of formic acid concentration $\left(\mathrm{x}_{1}\right)$ : experiments 1-3, 4-7, and 8-10 where the level of formic acid concentration was set to the value of $+1,0$, and -1 , respectively. 
Experiments 1-3 were done using the highest formic concentration while the dosage of $\mathrm{TiO}_{2}$ varied from the lowest level to the highest one. As can be seen from experiment 1 to 3 in Fig. 3 a for lignin samples, the TPC production increased by increasing the $\mathrm{TiO}_{2}$ dosage; highlighting the importance of an adequate photocatalyst concentration. This observation is in agreement with other studies (Gong et al., 2017; Kansal et al., 2008; Ma et al., 2008; Nair et al., 2016). In contrast, the increase of the $\mathrm{TiO}_{2}$ during wheat straw treatment was connected with decreased TPC production as shown in Fig. 3b. In addition, no appreciable changes can be found among experiment 1 (photocatalyst-free condition) and 2 (medium level of the photocatalyst used). This can be attributed to the fact that an uncontrolled photocatalysis using $\mathrm{TiO}_{2}$ would favor the attack on other parts of wheat straw (i.e. cellulose or hemicellulose) which does not result in the production of phenolics. subsequently, decreased at experiments 6 and 7 (denoted as center point in Fig. 3a). On the other hand, considering the same level experiments for wheat straw, no significant change occurred. Experiments 8, 9, and 10 where lignin or wheat straw was soaked in water without addition of any formic acid (level of -1 for formic acid concentration) showed the lowest production of TPC or even negative in the case of lignin. This confirms a role of formic acid in combination with $\mathrm{TiO}_{2}$ for an improved TPC in the entire process. This result is in line with the probe molecule experiments when no formic acid was used. At this condition, unselective direct degradation of the probe molecule happened. It was also observed that by further increasing $\mathrm{TiO}_{2}$ dosage, less TPC was produced for lignin sample. Thus, lignin would be mineralized due to harsher conditions provided by presence of $\mathrm{TiO}_{2}$ in a short manner of time, when no formic acid was used. In the case of wheat straw, the opposite effect of lignin samples was achieved (Fig. 3b). Particularly, in these experimental conditions, a slight increase in the TPC production was achieved by an increment of $\mathrm{TiO}_{2}$ dosage. This enhancement can be due to the direct effect of mediated radicals from $\mathrm{TiO}_{2}$ which agrees well with our previous study (Alvarado-Morales et al., 2017). Despite the decrease in TPC for lignin at experiments 8-9, it was observed that TPC for wheat straw was increased for these experiments. This could 
321 be due to the fact that the provided harsher conditions did not only exerted a strong oxidation action for

322 phenolics production by oxidation of lignin component. The radicals would favor the attack on other parts of 323 wheat straw which does not result in the production of phenolics. To study the effect of radicals on cellulose

324 or hemicellulose of wheat straw, sCOD \% change was introduced at the next step during model

325 development. For experiment 10 (control; only water), no change or slightly higher production of TPC for 326 lignin and wheat straw, respectively were found, which is in line with our previous study (Tsapekos et al., 327 2018).

328 Fig. S1 presents the time evolution of UV-vis spectra for the experiment ran at the center point conditions for 329 lignin and wheat straw samples. For both samples, the peak corresponding to phenolics at $280 \mathrm{~nm}$ increased 330 with an extension UV illumination time. Increased amount of phenolics was produced in the case of lignin 331 compared to the wheat straw sample. For wheat straw, there was no appreciable increase in the concentration 332 of phenolic compounds in the aqueous phase could be observed. The reason for this observation could be due 333 to the lower limited content of lignin in wheat straw (i.e. $26.7 \pm 2.4 \% \mathrm{TS}$ ). It is interesting to note that 334 phenolic production continuously increased with irradiation time, suggesting that overoxidation of the 335 produced phenolics to $\mathrm{CO}_{2}$ and $\mathrm{H}_{2} \mathrm{O}$ did not occur. Based on the conducted experiments, the TPC production $336 \%$ change after $180 \mathrm{~min}$ for lignin and $240 \mathrm{~min}$ for wheat straw were chosen for model development. 

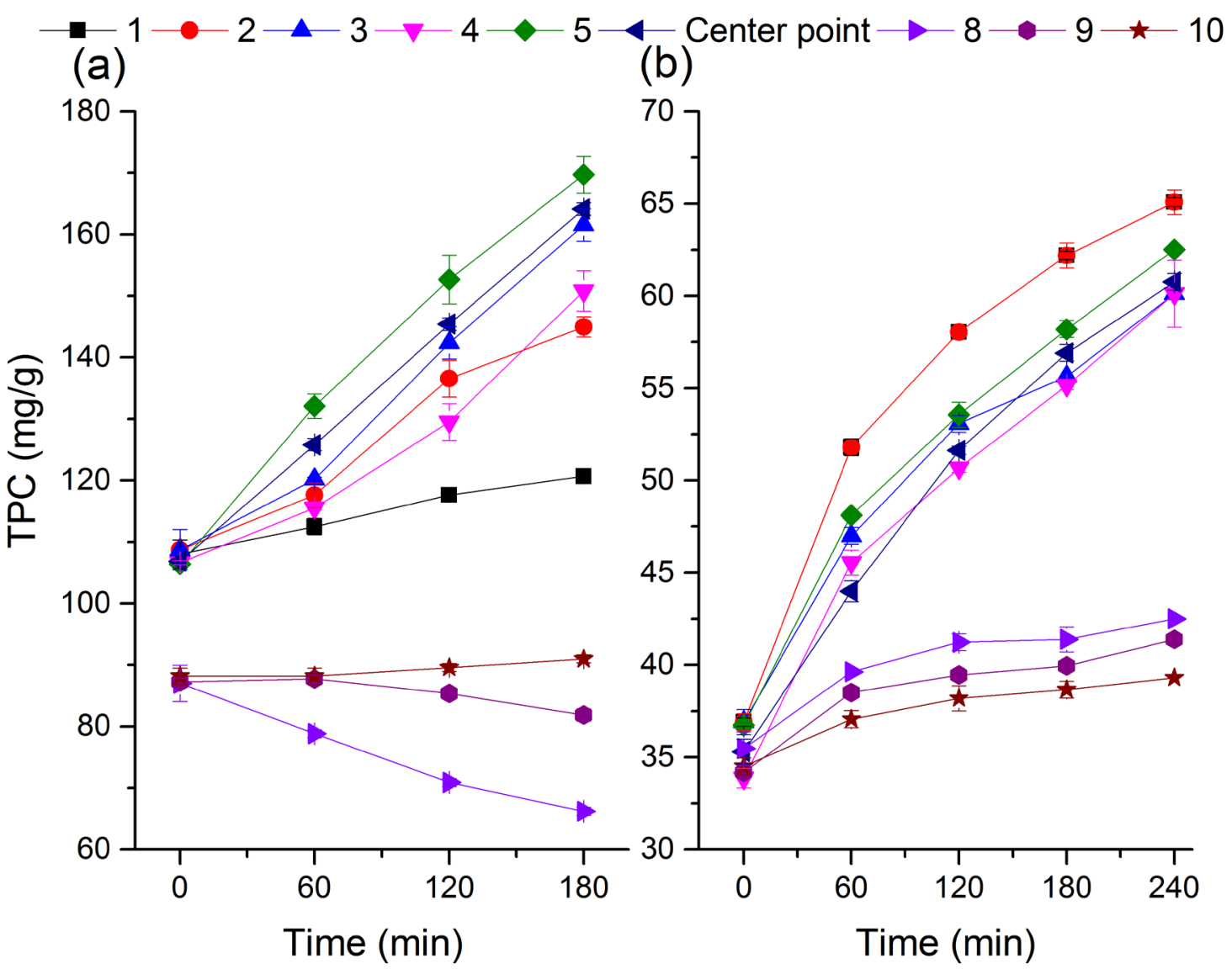

Fig. 3. TPC concentration $(\mathrm{mg} / \mathrm{g})$ as a function of time under different conditions according to the fCCD for a) lignin and b) wheat straw center point corresponds to the average of experiments 6-7. Fixed experimental conditions: lignin loading $0.2 \mathrm{~g} / \mathrm{L}$; wheat straw loading $1 \mathrm{~g} / \mathrm{L}$; final volume $100 \mathrm{~mL}$; saturated with air.

\subsection{Model development and validation ANOVA}

A fCCD design, of 10 experiments, was run in order to explore the effects of two independent variables on the responses in a systematic way. Two models were constructed based on the experimental results of the fCCD, namely Eqs. (15) and (16). In the case of wheat straw, an additional model was built based on sCOD $\%$ change expressed in the Eq. (17). The actual responses observed from running experiments are listed in Table 2. The final mathematical models associated with the responses were obtained after elimination of insignificant terms $(p>0.05)$. The final models for predicting the TPC and sCOD $\%$ change for treated lignin and wheat straw in terms of coded variables $\left(\mathrm{x}_{1}\right.$ : Formic acid and $\left.\mathrm{x}_{2}: \mathrm{TiO}_{2}\right)$ are:

TPC of lignin $\%$ change $=51.87+20.07 \times x_{1}+4.65 \times x_{2}+15.99 \times x_{1} \times x_{2}-40.76 \times \mathrm{x}_{1}^{2}$ 
TPC of wheat straw $\%$ change $=70.50+25.14 \times x_{1}-4.85 \times x_{1} \times x_{2}-27.06 \times \mathrm{x}_{1}^{2}$

sCOD of wheat straw $\%$ change $=55.30-38.67 \times x_{1}+13.83 \times \mathrm{x}_{1}^{2}-15.56 \times \mathrm{x}_{2}^{2}$

349 The adequacy of the model was justified through ANOVA and the results are shown in Table S1. The 350 models constructed were highly significant $(p \leq 0.0005)$ and the test of lack-of-fit was satisfactory 351 insignificant. Furthermore, the second-order polynomial models were highly significant for $95 \%$ confidence 352 level as shown by the $F$-ratios of 111.543 and 167.732 for TPC \% change of lignin and wheat straw, 353 respectively. F-ratio was found to be 41.244 for sCOD \% change. The fitted model was further evaluated by 354 the correlation coefficient $\left(R^{2}\right)$. According to the ANOVA results (Table $\mathrm{S} 1$ ), $R^{2}$ values were in good 355 agreement with the adjusted $R^{2}$, indicating that the effects included in the models are sufficient for modeling the responses. All predictive models presented in this study can be used for estimation of the TPC and SCOD $\%$ change within the ranges of the experimental region.

\subsection{Response surface plotting for evaluation of operational parameters and optimization of the}

Fig. 4 presents the response surface graphs which are the graphical representation of the regression equations Eqs. (15) - (17) values within the levels $[-1,+1]$. The response surface graph of Eq. (15) is presented in Fig. $4 \mathrm{a}$, where the predicted TPC $\%$ change is plotted as a function of the formic acid concentration and $\mathrm{TiO}_{2}$ dosage in the coded form. As shown, the TPC \% change increased with increasing formic acid concentration. The formic acid concentration appears to have had the strongest effect on TPC change of lignin, which is also reflected in Eq. (15), as the magnitude of the coefficient in front of $\mathrm{x}_{1}$ has the highest value with a positive sign. The maximum TPC change for lignin $(\approx 62 \%)$ was observed in the level of formic acid from 0.14 to 0.80 while $\mathrm{TiO}_{2}$ dosage from 0.61 to 0.96 ; and, $\mathrm{x}_{1}$ resulted in low TPC change when set at the maximum or minimum level of the experimental range. Further increase of formic acid concentration from 0.80 to 1 coincided with depletion in TPC $\%$ change. This observation indicates that under these conditions, the amount of ${ }^{\bullet} \mathrm{OH}$ and $\mathrm{H}^{\bullet}$ formed by water homolysis (Eq. (6)) is inadequate to react with formate or formic acid to produce $\mathrm{CO}_{2}{ }^{\bullet-}$ (Eqs. (7) - (10)). Thus, the $\mathrm{CO}_{2}{ }^{\bullet-}$ formation became independent of formic acid concentration. All of these effects are expressed in the model by the quadratic term of this parameter $\left(\mathrm{x}_{1}^{2}\right)$. 
Optimization of the input space of the reaction (i.e. Eq. (15)) was obtained with the highest TPC increase of $37464.0 \pm 4.121 \%$ at the conditions as follows: formic acid concentration $=0.4 \mathrm{M}\left(\mathrm{x}_{1}=+0.33\right)$ and $\mathrm{TiO}_{2}$ dosage $375=0.2 \mathrm{~g} / \mathrm{L}\left(\mathrm{x}_{2}=+1\right)$. The validation of predicted optimized conditions was done by conducting the experiment at the aforementioned conditions. Indeed, the comparison between the predictive $(64.0 \pm 4.121 \%)$ and experimental results $(63.420 \pm 3.511 \%)$ had a very good agreement as they did not differ significantly. The increase obtained experimentally corresponded to $173.431 \pm 2.970 \mathrm{mg} / \mathrm{g}$ TPC with the starting TPC concentration of $106.40 \pm 0.33 \mathrm{mg} / \mathrm{g}$.

The effects of $x_{1}$ and $x_{2}$ on the TPC $\%$ change of wheat straw is demonstrated in Fig. $4 b$; which is the graphical representation of Eq. (16). As shown, by increasing $\mathrm{x}_{1}$, the TPC $\%$ increased almost irrespectively of $\mathrm{x}_{2}$. As indicated in Eqs. (7) - (8), ${ }^{\bullet} \mathrm{OH}$ availability in the presence of formate or formic acid, enhanced the formation of $\mathrm{CO}_{2}{ }^{\bullet}$. As mentioned above, the lamp itself is capable of production of ${ }^{\bullet} \mathrm{OH}$ and $\mathrm{H}^{\bullet}$ and on top of this, the presence of $\mathrm{TiO}_{2}$ provided the additional source for ${ }^{\bullet} \mathrm{OH}$ (Eq. (13)). In this regard, the increase of $\mathrm{x}_{2}\left(\mathrm{TiO}_{2}\right.$ dosage $)$ affected the reaction insignificantly. This implies the independence of TPC change from the addition of $\mathrm{TiO}_{2}$. Moreover, TPC change had a rapid increase with increasing $\mathrm{x}_{1}$ within the level of -1 to 0 . Subsequently, the further increase of $\mathrm{x}_{1}(0$ to 1$)$ had no significant change in the reactivity, indicating that there was an optimum concentration of formic acid. In other words, $\mathrm{x}_{1}$ played an influential role when its level declined to 0 and less. As it discussed earlier in Eqs. (8) - (9), the increase in formic acid concentration has a positive effect on the production of $\mathrm{CO}_{2}{ }^{\bullet}$, thus contributing directly to the increase of TPC. Fig. 4c presents the effect of $x_{1}$ and $x_{2}$ on the sCOD \% change of wheat straw resulting from Eq. (17). The response was plotted as a function of two factors varying in the factorial part of the design $[-1,+1]$. It was observed that that highest SCOD $\%$ change $(\approx 106 \%)$ was obtained at low $\mathrm{x}_{1}$ and middle $\mathrm{x}_{2}$. In the real value format, sCOD $\%$ decreased with the increase in formic acid concentration, while sCOD $\%$ change increased with increase in $\mathrm{TiO}_{2}$ up to $0.05 \mathrm{~g} / \mathrm{L}$ after which continuous decrease was observed. It is interesting to note that, sCOD $\%$ change (Fig. 4c) showed an irreversible trend with TPC $\%$ change (Fig. 4b). This proposes, the sCOD serves as an indirect measurement of TPC: the increase in solubilized particulate matter \% would result in the decrease in TPC \%. In other words, the solubilization of particulate matter must be kept low if 
the TPC increase is taken into consideration. To this end, the experimental conditions must be set at the highest level of $\mathrm{x}_{1}$ and low or high values of $\mathrm{x}_{2}$ to minimize $\mathrm{SCOD} \%$ change. It is important to note that setting the value of $\mathrm{x}_{2}$ at the low level (i.e. photocatalyst-free condition) is more beneficial compared to the highest level of $\mathrm{x}_{2}$ which involves the additional cost of separation for the used photocatalyst. According to Figs. $4 \mathrm{~b}$ and $4 \mathrm{c}$, the optimal conditions of the pretreatment of wheat straw fibers for maximum TPC and minimum sCOD $\%$ change corresponded to $0.35 \mathrm{M}$ formic acid $\left(\mathrm{x}_{1}=+0.75\right)$ and photocatalyst-free condition $\left(\mathrm{x}_{2}=-1\right)$. The prediction of Eq. (16) for the TPC change under these conditions, corresponds to $77.0 \pm 2.893 \%$, and based on Eq. (17) for to a $17.0 \pm 7.734 \%$ increase of sCOD. Finally, these conditions were verified experimentally, suggesting the good agreement between the predicted and observed $(75.822 \pm$ $3.071 \%$ for TPC and $19.212 \pm 5.341 \%$ for sCOD) values. The treated wheat straw solution at the optimized conditions contained $66.802 \pm 2.281 \mathrm{mg} / \mathrm{g}$ TPC.
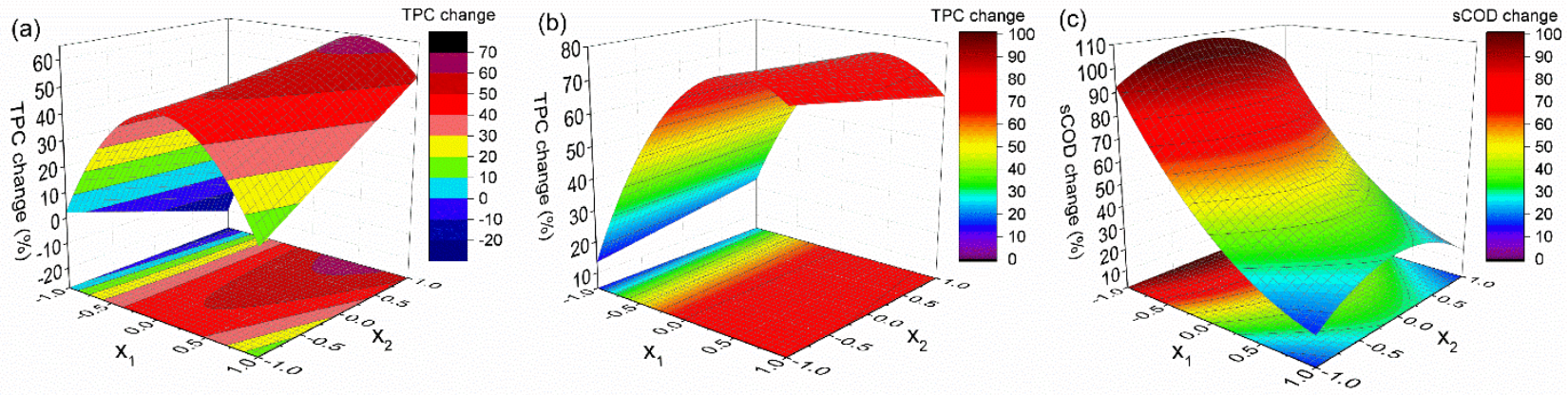

Fig. 4. Surface plots of a) TPC $\%$ change as a function of formic acid concertation $\left(\mathrm{x}_{1}\right)$ and $\mathrm{TiO}_{2}$ dosage $\left(\mathrm{x}_{2}\right)$ at irradiation time of $180 \mathrm{~min}$ for lignin, and surface plots of b) TPC \% change, and c) sCOD \% change as a function of formic acid concertation $\left(\mathrm{x}_{1}\right)$ and $\mathrm{TiO}_{2}$ dosage $\left(\mathrm{x}_{2}\right)$ at irradiation time of 240 min for wheat straw. [Fixed experimental conditions: lignin loading $0.2 \mathrm{~g} / \mathrm{L}$; wheat straw loading $1 \mathrm{~g} / \mathrm{L}$; final volume $100 \mathrm{~mL}$; saturated with air].

\subsection{Characterization of optimized conditions}

\subsubsection{Qualification of the liquid phase}

Phenolics produced at the optimized conditions were qualified and the GC/MS total ion chromatograms are shown in Fig. 5 for both lignin and wheat straw samples. The corresponding retention time, molecular 
weight, and other identifiable compounds are listed in Table 3, in which their corresponding charge-to-mass ratios $(\mathrm{m} / \mathrm{z})$ are also listed. In the case of lignin, the main reaction products were guaiacol, 2-ethylphenol, and vanillin. The presence of 2-ethylphenol and vanillin demonstrates the occurrence of oxidation during the photocatalytic reaction, which is in agreement with literature (Chen et al., 2018; Gong et al., 2017; Nair et al., 2016). Based on experimental and product characterization results together with a bond dissociation energy (BDE) of major bonds within lignin inter unit linkage from literature, a possible lignin decomposing pathway is proposed for lignin oxidation. In summary, depolymerization of lignin led to production of phenolics as the major product. This is supported by the fact that all the products detected were phenolics (e.g. guaiacol, 2-ethylphenol, and vanillin). The identity of these products was found to support the $\mathrm{H}$ abstraction pathway, as illustrated in the degradation pathway of probe molecule in the section of 3.1.1. It is likely that the most pronounced reactions in the case of lignin are degradation via $\beta-\mathrm{O}-4$ and $\mathrm{C}_{\alpha}-\mathrm{C}_{\beta}$, scission reactions. It could be due to the fact that the lowest and second lowest of BDE among linkages in lignin are $\mathrm{C}_{\beta}-\mathrm{O}-4(245.3 \mathrm{~kJ} / \mathrm{mol})$ and $\mathrm{C}_{\alpha}-\mathrm{C}_{\beta}(259.2 \mathrm{~kJ} / \mathrm{mol})$, indicating these bonds are relatively easier to break during the oxidation process (Feng et al., 2019).

Diverse peaks were also detected for the treated wheat straw (Fig. 5). Specifically, isophthalaldehyde, phenol, 3-methylindole, 1-naphthalenol, phthalimide, and 3-phenyl furan were obtained. It is interesting to note the presence of nitrogen derived compounds with - amine (NH) groups such as 3-methylindole and phthalimide. It is worth mentioning that untreated wheat straw contained nitrogen element based on elemental analysis (Table 4). The presence of these nitrogenated compounds into liquid phase was justified based on the cleavage of the $\mathrm{C}-\mathrm{N}$ bond due to the radical reactions. The mixture of nitrogen-compounds formed during oxidation was also mentioned elsewhere (Prado et al., 2013). In summary, solid wheat straw was undergone the degradation pathway followed by cleavage of the $\mathrm{C}-\mathrm{N}$ bond to release the mixture of nitrogen-compounds in the liquid phase alongside phenolic compounds via $\mathrm{H}$ abstraction. 


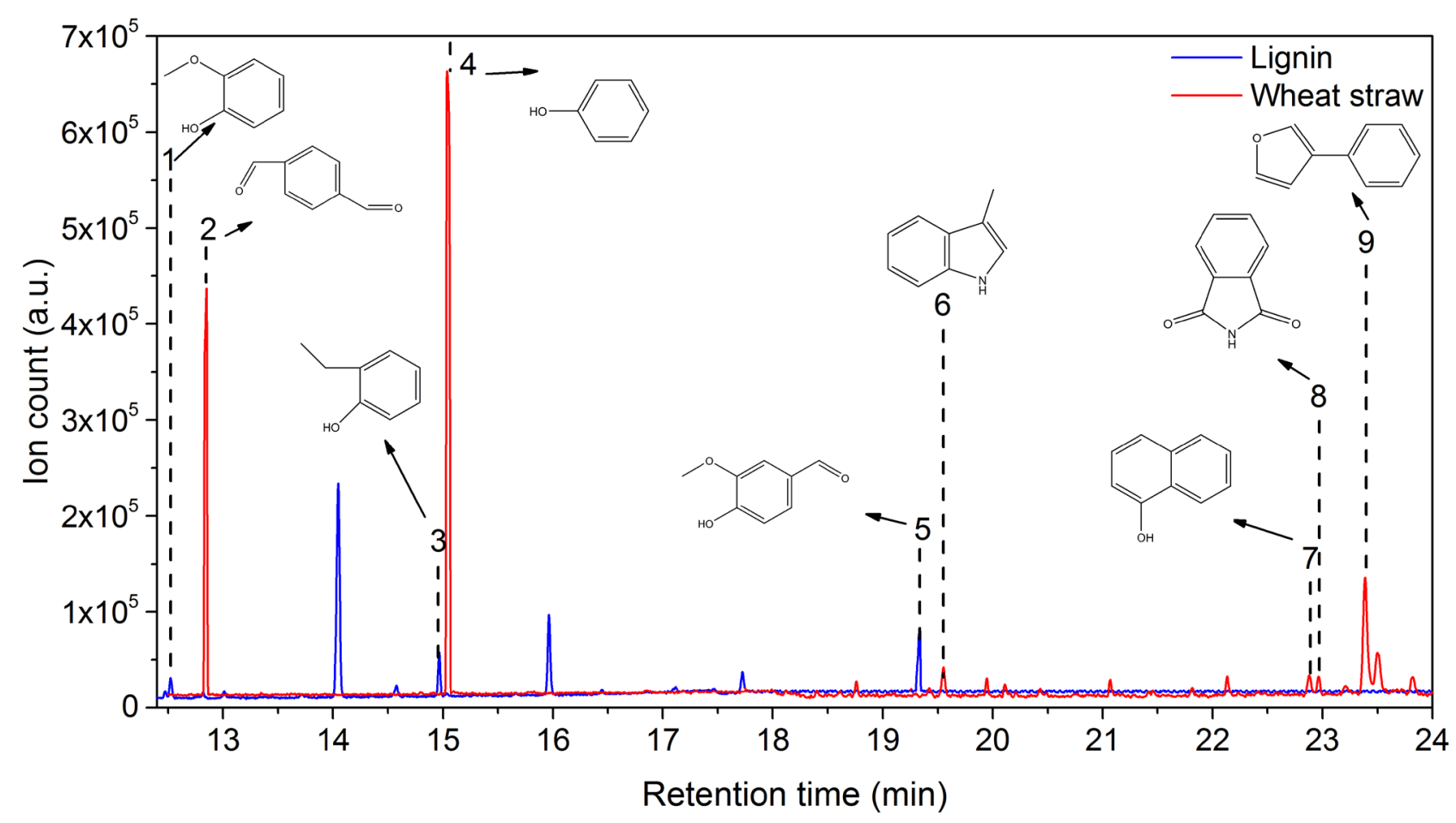

Fig. 5. GC/MS total ion chromatograms of phenolics obtained from photocatalysis of lignin and wheat straw at the optimized conditions (for lignin: formic acid concentration $=0.4 \mathrm{M}\left(\mathrm{x}_{1}=+0.33\right)$ and $\mathrm{TiO}_{2}$ dosage $=0.2$ $\mathrm{g} / \mathrm{L}\left(\mathrm{x}_{2}=+1\right)$; for wheat straw: $0.35 \mathrm{M}$ formic acid $\left(\mathrm{x}_{1}=+0.75\right)$ and photocatalyst-free condition $\left.\left(\mathrm{x}_{2}=-1\right)\right)$. [Fixed experimental conditions: lignin loading $0.2 \mathrm{~g} / \mathrm{L}$; wheat straw loading $1 \mathrm{~g} / \mathrm{L}$; final volume $100 \mathrm{~mL}$; saturated with air]. The peaks correspond to 1) guaiacol, 2) isophthalaldehyde, 3) 2-ethylphenol, 4) phenol, 5) vanillin, 6) 3-methylindole, 7) 1-naphthalenol, 8) phthalimide, 9) 3-phenyl furan.

\subsubsection{Qualification of the solid phase}

Negligible differences $(p>0.05)$ were detected for carbon, hydrogen, and oxygen contents among untreated and treated wheat straw (Table 4). Monitoring of the nitrogen element showed that significantly $(p<0.05)$ lower content $(0.46 \pm 0.04 \% \mathrm{wt})$ was observed in the treated sample at the optimized conditions compared to the untreated one $(0.57 \pm 0.00 \% \mathrm{wt})$. The decrease in the nitrogen content in the wheat straw's solid fibers after $\mathrm{CO}_{2}{ }^{-}-$mediated reaction suggests that nitrogenated compounds in the liquid phase were produced. It also implies that $\mathrm{H}$ abstraction and cleavage of the $\mathrm{C}-\mathrm{N}$ bond is more preferably occurring with higher rates compared to $\mathrm{C}-\mathrm{C}$ bond. This result is in line with previous research when photocatalysis of nitrogenous compounds was examined (Klare et al., 2000). It is interesting to note that $\mathrm{C} / \mathrm{N}$ ratio of the untreated and 
treated samples were found to be 77.3 and 96.9 , respectively. Moreover, the resulting fibers give higher heating value (HHV) of $19.33 \mathrm{MJ} / \mathrm{kg}$ (based on Gumz's formula (Channiwala and Parikh, 2002)) compared to $18.51 \mathrm{MJ} / \mathrm{kg}$ for the untreated sample, presenting a great potential to produce alternative fuels.

Solid phase fibers obtained after the oxidation process of the wheat straw was characterized with XRD, FTIR, and SEM techniques and the resulting graphs are shown in Fig. 6. The XRD patterns of untreated and treated fibers are presented in Fig. 6a. The feature diffraction peaks of the treated sample exhibit similar diffraction peaks with higher intensity compared to the untreated with two prominent peaks at $18^{\circ}$ and $22.5^{\circ}$ corresponding to cellulose and the amorphous region, often lignin and hemicellulose, respectively (Segal et al., 1959). Crystalline cellulose associated with the intermolecular hydrogen bonding between the chains leads to the biomass recalcitrance, eliminating substrate's degradability (Lee et al., 2014). The CI expresses the ratio of crystalline cellulose to amorphous region, which is s a suitable indicator to evaluate the effect of pretreatment on biomass crystallinity. A low CI indicates a high crystalline structure and a low crystalline structure is represented by a high CI (Moodley and Kana, 2017). After calculating the (CI) by Eq. (5), these values found to be $48.93 \%$ for the untreated and $51.92 \%$ for the treated, showing $3 \%$ of increment after the treatment. The increase in $\mathrm{CI}$ is attributed to the fact that hemicellulose and lignin in the amorphous region were partially removed during the pretreatment as mentioned above.

FTIR spectra of untreated and treated wheat straw at the optimized conditions were done to investigate the change in the main functional groups and chemical structure. As shown in Fig. 6b, both samples showed a peak at $3343 \mathrm{~cm}^{-1}$ corresponding to O-H stretching in hydroxyl group (Kang et al., 2018). The difference in the intensity of the two samples can be attributed to the water absorption of each sample. Peaks at 2920 and $2851 \mathrm{~cm}^{-1}$ are ascribed to C-H stretching inside cellulose which showed the higher intensity after treatment (Dehghani et al., 2015). Peak at $1732 \mathrm{~cm}^{-1}$ is indicative of $\mathrm{C}=\mathrm{O}$ bond of hemicellulose remained the same after treatment, suggesting hemicellulose was not notably under attack during treatment (Feng Xu et al., 2013; Gandolfi et al., 2014; Mou et al., 2014). Destruction of lignin structure was shown by reduction in peak intensity at $1648 \mathrm{~cm}^{-1}(\mathrm{C}=\mathrm{O}$ linkage; conjugated carbonyls attributed to coumaryl easter group (Hage et al., 2009)) and at $1030 \mathrm{~cm}^{-1}$ (C-H, C-O linkages in the guaiacol structure and bond deformation (Feng Xu et al., 2013; Mainka et al., 2015; Sunthornvarabhas et al., 2017)) compared to untreated samples. Deformations 
in aromatic rings appeared at $796 \mathrm{~cm}^{-1}$, and there was no appreciable change observed among two samples

487 (Mou et al., 2014). Overall, a comparison between the untreated and treated wheat straw, lignin degradation 488 took place with various peaks belonging to lignin $\left(1648 \mathrm{~cm}^{-1} \mathrm{C}=\mathrm{O}\right.$ bond, $1030 \mathrm{~cm}^{-1} \mathrm{C}-\mathrm{H}$, and $\mathrm{C}-\mathrm{O}$ bonds $)$ 489 showing a significant reduction in peaks. Moreover, peaks of hemicellulose $\left(1732 \mathrm{~cm}^{-1} \mathrm{C}=\mathrm{O}\right.$ conjugates $)$ and 490 cellulose (2920-2851 cm $\mathrm{cm}^{-1}$ and $1366 \mathrm{~cm}^{-1} \mathrm{C}-\mathrm{H}$ bonds) remained at largely the same shape. Hence, it can be 491 concluded that $\mathrm{CO}_{2}{ }^{-}$assisted reaction favored removal of peaks related to lignin. TCI was calculated by taking the ratio of peak areas at 1372 and $2920 \mathrm{~cm}^{-1}$ from FTIR spectra. TCI values were found to be 0.97 493 and 1.02 for untreated and the treated sample, respectively. The slight increase after treatment as compared 494 to untreated could be due to decrease/removal in peaks belongs to lignin, which is further corroborated the 495 results obtained by XRD analysis. Similar observation has also been obtained where an increase in CI and 496 TCI were observed (Mainka et al., 2015; Moodley and Kana, 2017; Pan et al., 2017). SEM analysis of 497 treated and untreated samples are shown in Figs. 6c and 6d. As can be seen in Fig. 6c, untreated wheat straw 498 showed long unbroken fibers with a smooth surface arranged in bundles. However, the treated samples (Fig. 499 6d) had much rougher surfaces along with cracking surface into small parts, while unbroken chains of 500 cellulose underneath were also preserved. Therefore, it can be concluded that pretreatment disrupted lignin 501 structure while preserving cellulose strands, indicating that the major biodegradable fraction has not been 502 extensively attacked. Thus, the SEM observations further strengthen XRD and FTIR results. 

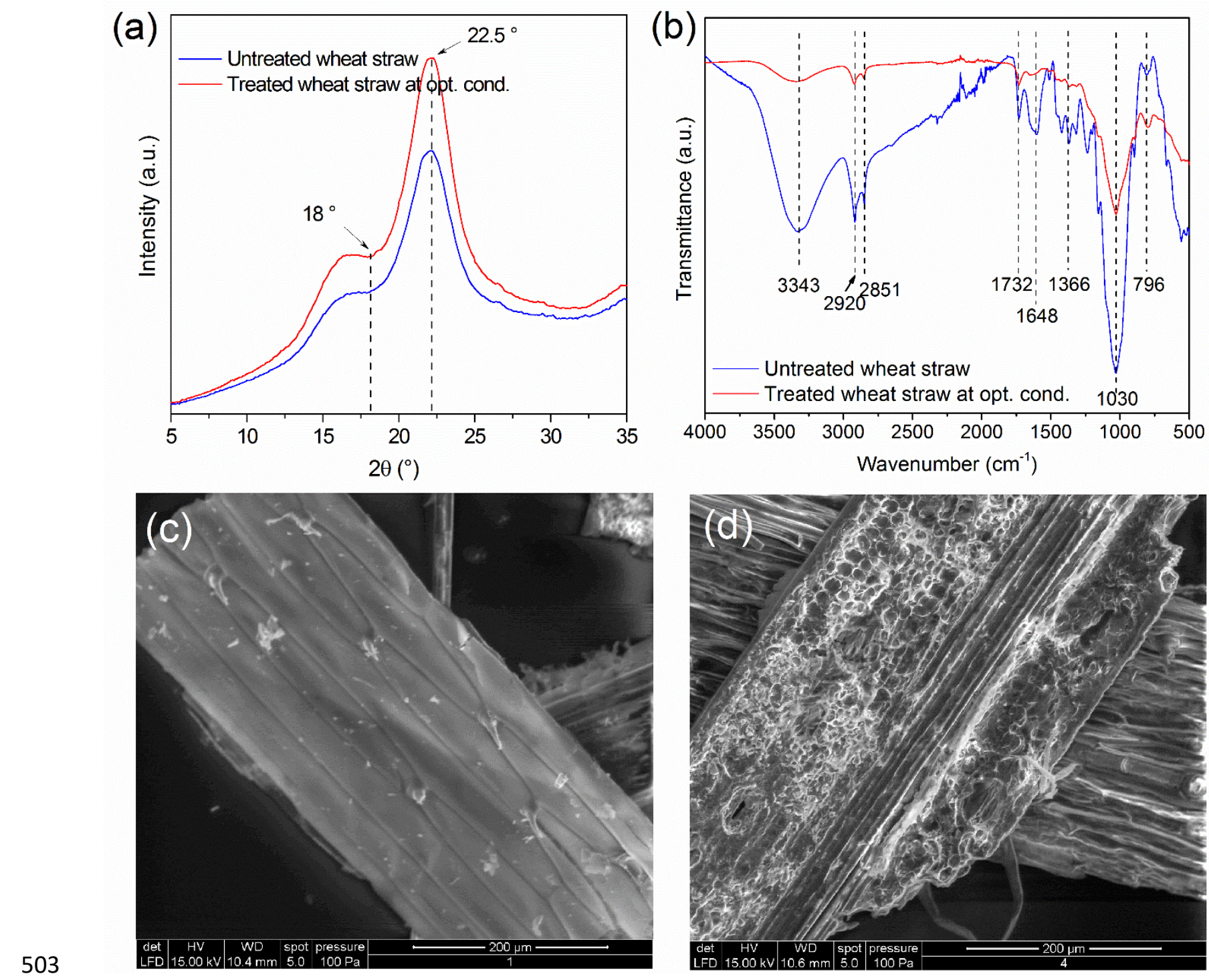

Fig. 6. (a) XRD and (b) FTIR spectra of the wheat straw sample before and after pretreatment, (c, d) SEM

images of (c) untreated wheat straw and (d) treated wheat straw at the optimized conditions.

\subsection{Cycle test}

The cycle test was designed with the aim of re-using the formic acid solution in further pretreatment cycles.

508 Besides the possibility of formic acid recovery, the formed phenolics are not susceptible to overoxidation.

509 Hence, for every cycle, the content of pretreated fibers was replaced with fresh biomass using the same

510 solution. At the end of $1^{\text {st }}$ cycle, TPC increased to $65.081 \pm 6.781 \mathrm{mg} / \mathrm{g}$ corresponding to $75.561 \pm 0.830 \%$

511 increase compared to zero time (Fig. 7). The obtained result is in line with the prediction of Eq. (16) for the

512 optimized conditions $(77.0 \pm 2.893 \%$ associated with the final TPC concentration of $66.802 \pm 2.281 \mathrm{mg} / \mathrm{g}$ in 
the treated solution) which justifies again the validity of the model. For the $2^{\text {nd }}$ and $3^{\text {rd }}$ cycles the TPC increased by $44.392 \pm 3.280 \%$ and $10.30 \pm 1.961 \%$, respectively. The final value of TPC at the end of $2^{\text {nd }}$ and $3^{\text {rd }}$ cycles were $93.972 \pm 3.161 \mathrm{mg} / \mathrm{g}$ and $103.651 \pm 5.964 \mathrm{mg} / \mathrm{g}$, respectively, which is comparable with the value of $94.6 \mathrm{mg} / \mathrm{g}$ reported in our previous study (Tsapekos et al., 2018). It is important to note that these observations are not in accordance with predicted results from Eq. (16). The reason for the inadequate prediction accuracy can be attributed to the declined concentration of formic acid at the beginning of $2^{\text {nd }}$ and $3^{\text {rd }}$ cycles. HPLC measurement was carried out to determine the concentration of formic acid at the beginning of each cycle. As shown in Fig. 7, the measurements showed a decrease in the concentration of formic acid after each cycle. At the end of $3^{\text {rd }}$ cycle, the concentration of formic acid reached $0.06 \pm 0.01 \mathrm{M}$.

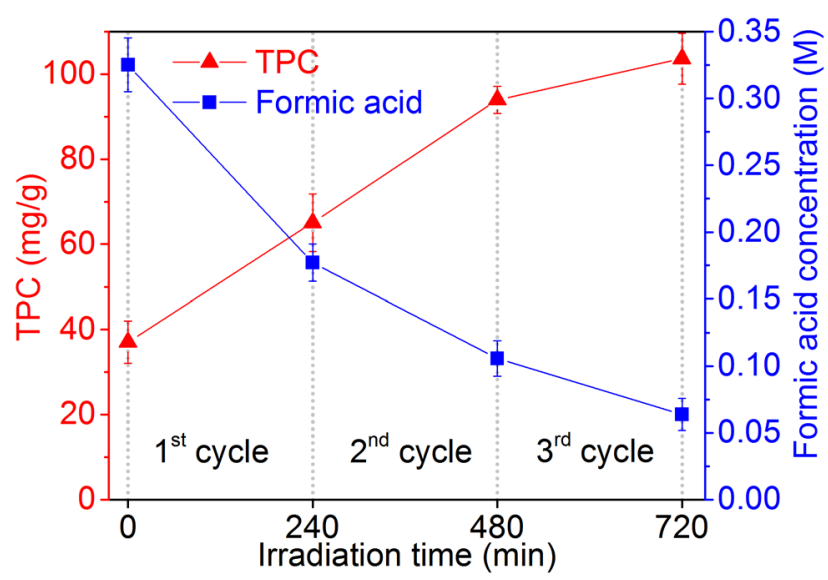

Fig. 7. TPC and formic acid concentration during three consecutive cycles for the wheat straw sample at the optimized conditions with $0.35 \mathrm{M}$ formic acid $\left(\mathrm{x}_{1}=+0.75\right)$ and photocatalyst-free condition $\left(\mathrm{x}_{2}=-1\right)$. [Fixed experimental conditions: wheat straw loading $1 \mathrm{~g} / \mathrm{L}$; final volume $100 \mathrm{~mL}$; saturated with air].

\subsection{BMP assays}

Fig. 8 shows the cumulative methane production over the incubation period. $1^{\text {st }}$ and $2^{\text {nd }}$ cycles showed marginally equal methane production with the value of $276.7 \pm 18.78$ and $275.0 \pm 24.32 \mathrm{mLCH}_{4} / \mathrm{gVS}$, respectively. The untreated wheat straw sample reached its highest production $(248.4 \pm 12.29 \mathrm{mLCH} / \mathrm{gVS})$ towards the end of the test whereas; the treated wheat straw sample was fully digested by the $18^{\text {th }}$ day. Hence, apart from the $11.0 \%$ increase in bioenergy production, treated fibers showed also faster degradation rate, as the highest yield was produced in a shorter period compared to untreated biomass. Morales et al. (2017) conduct a BMP assay on photocatalytically treated wheat straw using $\mathrm{TiO}_{2}$ and achieve $37 \%$ higher 
535 further validated the efficiency of the applied pretreatment process in the presence of formic acid. The 536 lignocellulosic tissue was disrupted increasing the access for the microbes to the hemicellulose and cellulose, increasing the digestion rate and finally, aiding to reach higher methane production.

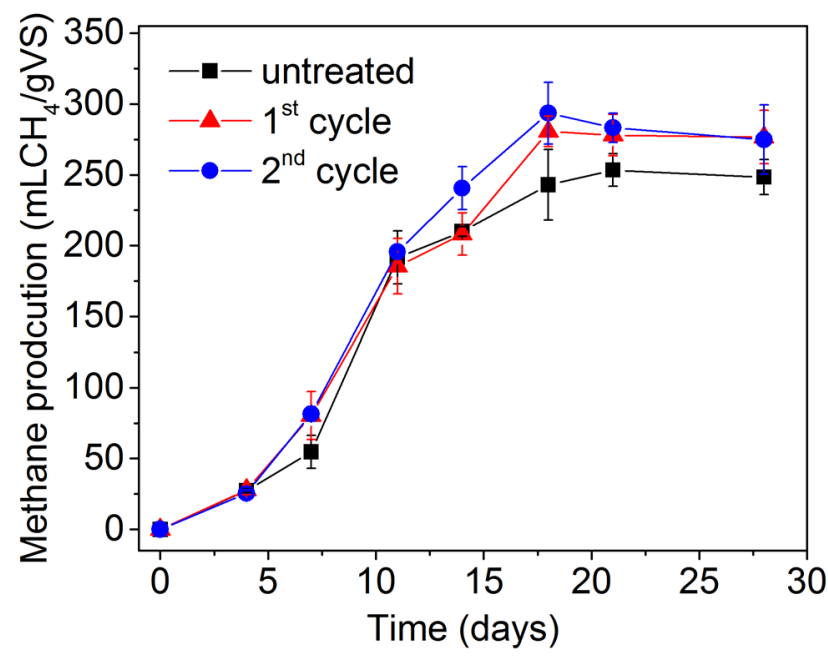

539 Fig. 8. BMP assay of untreated wheat straw along with $1^{\text {st }}$ cycle and $2^{\text {nd }}$ cycle pretreated fibers.

\subsection{Implication to industrial applications}

Lignin is a major discharge of $2 \mathrm{G}$ ethanol plant and often discarded only for its heat value due to its inherent complex structure and underdeveloped lignin valorization technologies. This waste stream is expected to exponentially increase with an increasing number of $2 \mathrm{G}$ bioethanol plants being built. Lignin usage is currently limited to low- and medium-value applications (e.g. binding and dispersing agents), representing a market of \$730 M (Hämäläinen et al., 2018). Other markets include vanillin production (\$192 M) and cement additives $(\$ 176 \mathrm{M})$, as detailed by Lux Research report (Lux, 2014). To develop any strategy for lignin valorization, it would be preferred to select the pretreatment under mild conditions avoiding high pressure, temperatures, and hazardous and expensive chemical catalysts. Our proposed approach complies with this fact, thus lowering environmental impact. Apart from turning wheat straw into liquid phenolics, the process is able to generate biogas from solid leftover residue; thus complying with "zero" scheme waste

551 production. In this regard, as far as phenolics production is concerned, $65.081 \pm 6.781$ and $93.972 \pm 3.161$ $552 \mathrm{mg} / \mathrm{g}$ after $1^{\text {st }}$ and $2^{\text {nd }}$ cycle were obtained, respectively. The methane production from solid resides reached 
the value of $276.7 \pm 18.78$ and $275.0 \pm 12.29 \mathrm{mLCH}_{4} / \mathrm{gVS}$ after $1^{\text {st }}$ and $2^{\text {nd }}$ cycle. Only formic acid $(0.35 \mathrm{M})$ upon a doped medium pressure UV lamp irradiation used in this method, would not influence the cost of operation significantly. The electrical energy consumption by the UV-lamp was considered as solely energy used during the pretreatment. For the used lamp, a value of $0.061 \mathrm{kWh}$ per unit of volume $\left(\mathrm{m}^{3}\right)$ of the suspension treated per unit of time (min) was determined experimentally according to Hansen et al. (Hansen et al., 2013). Hence, $\mathrm{HCOOH}$ reaction upon a doped medium pressure UV lamp irradiation is believed to push forward the future prospects of biorefineries with greener pretreatment process and use more efficiently feedstocks and wastes in a circular economy-frame.

\section{Conclusion}

A novel $\mathrm{UV} / \mathrm{TiO}_{2} / \mathrm{HCOOH}$ reaction upon a doped medium pressure UV lamp irradiation was proposed to depolymerize lignin for production phenolic compounds. Efficient $\mathrm{H}$ abstraction from 2,3-

dihydrobenzofuran as $\beta$-O-4 linkages representative of lignin was observed. The addition of methyl viologen proved that $\mathrm{CO}_{2}{ }^{\bullet-}$ was mainly responsible for TPC production. This pretreatment method was adopted to test the technical feasibility for production of high value products from lignin and wheat straw as an actual lignocellulosic biomass. The highest concertation of TPC obtained from lignin was $173.431 \pm 2.970 \mathrm{mg} / \mathrm{g}$ at optimized conditions of $0.4 \mathrm{M}$ formic acid and $0.2 \mathrm{~g} / \mathrm{L} \mathrm{TiO}_{2}$. The highest TPC achieved in the case of wheat straw was $66.802 \pm 2.281 \mathrm{mg} / \mathrm{g}$ corresponded to the optimal point of $0.35 \mathrm{M}$ formic acid and freephotocatalyst condition. It was found that free-photocatalyst condition promoted the production of TPC in the presence of formic acid. The highest TPC production after $3^{\text {rd }}$ cycle was $103.651 \pm 5.964 \mathrm{mg} / \mathrm{g}$, highlighting the advantage of this pretreatment for producing valuable compounds under facile environment. The solid leftover products showed increased methane production, achieving $11.0 \%$ increase compared to the untreated wheat straw. This work provides an environment-friendly pretreatment alternative for effective production of high-value products (phenolics and methane).

\section{Acknowledgments}

The authors thank Hector Garcia for technical assistance.

\section{References}


Ainsworth, E.A., Gillespie, K.M., 2007. Estimation of total phenolic content and other oxidation substrates in plant tissues using Folin-Ciocalteu reagent. Nat. Protoc. 2, 875-877. doi:10.1038/nprot.2007.102

Alvarado-Morales, M., Tsapekos, P., Awais, M., Gulfraz, M., Angelidaki, I., 2017. TiO 2 /UV based photocatalytic pretreatment of wheat straw for biogas production. Anaerobe 46, 155-161. doi:10.1016/j.anaerobe.2016.11.002

Angelidaki, I., Karakashev, D., Batstone, D.J., Plugge, C.M., Stams, A.J.M., 2011. Biomethanation and Its Potential. Methods Methane Metab. Part A 494, 327-351. doi:10.1016/B978-0-12-385112-3.00016-0

APHA, 1998. Standard Methods for Examination of Water and Wastewater, American Public Health Association (APHA). Washington, DC, USA.

Berkovic, A.M., Bertolotti, S.G., Villata, L.S., Gonzalez, M.C., Pis Diez, R., Mártire, D.O., 2012. Photoinduced reduction of divalent mercury by quinones in the presence of formic acid under anaerobic conditions. Chemosphere 89, 1189-1194. doi:10.1016/J.CHEMOSPHERE.2012.07.019

Berkovic, A.M., Gonzalez, M.C., Russo, N., del Carmen Michelini, M., Diez, R.P., Mártire, D.O., 2010. Reduction of Mercury(II) by the Carbon Dioxide Radical Anion: A Theoretical and Experimental Investigation. J. Phys. Chem. A 114, 12845-12850. doi:10.1021/jp106035m

Brodeur, G., Yau, E., Badal, K., Collier, J., Ramachandran, K.B., Ramakrishnan, S., 2011. Chemical and Physicochemical Pretreatment of Lignocellulosic Biomass: A Review. Enzyme Res. 2011, 1-17. doi:10.4061/2011/787532

Channiwala, S.A., Parikh, P.P., 2002. A unified correlation for estimating HHV of solid, liquid and gaseous fuels. Fuel 81, 1051-1063. doi:10.1016/S0016-2361(01)00131-4

Chen, J., Liu, W., Song, Z., Wang, H., Xie, Y., 2018. Photocatalytic Degradation of $\beta-O-4$ Lignin Model Compound by In2S3Nanoparticles Under Visible Light Irradiation. Bioenergy Res. 11, 166-173. doi:10.1007/s12155-017-9886-8

Dehghani, M., Karimi, K., Sadeghi, M., 2015. Pretreatment of rice straw for the improvement of biogas 
604 Dong, H., Zeng, G., Tang, L., Fan, C., Zhang, C., He, X., He, Y., 2015. An overview on limitations of TiO2605 based particles for photocatalytic degradation of organic pollutants and the corresponding countermeasures. Water Res. 79, 128-146. doi:10.1016/j.watres.2015.04.038

Feng, P., Wang, H., Lin, H., Zheng, Y., 2019. Selective production of guaiacol from black liquor: Effect of solvents. Carbon Resour. Convers. 2, 1-12. doi:10.1016/J.CRCON.2018.07.005

Feng Xu, Jianming Yu, Tesfaye Tesso, Floyd Dowell, Donghai Wang, 2013. Qualitative and quantitative analysis of lignocellulosic biomass using infrared techniques : A mini-review. Appl. Energy 104, 801809. doi:10.1016/j.apenergy.2012.12.019

Gandolfi, S., Ottolina, G., Consonni, R., Riva, S., Patel, I., 2014. Fractionation of hemp hurds by organosolv pretreatment and its effect on production of lignin and sugars. ChemSusChem 7, 1991-1999. doi:10.1002/cssc.201301396

Gong, J., Imbault, A., Farnood, R., 2017. The promoting role of bismuth for the enhanced photocatalytic oxidation of lignin on Pt-TiO 2 under solar light illumination. Appl. Catal. B Environ. 204, 296-303. doi:10.1016/j.apcatb.2016.11.045

Gu, X., Lu, S., Fu, X., Qiu, Z., Sui, Q., Guo, X., 2017. Carbon dioxide radical anion-based UV/S2O82-/HCOOH reductive process for carbon tetrachloride degradation in aqueous solution. Sep. Purif. Technol. 172, 211-216. doi:10.1016/J.SEPPUR.2016.08.019

Hage, R. El, Brosse, N., Chrusciel, L., Sanchez, C., Sannigrahi, P., Ragauskas, A., 2009. Characterization of milled wood lignin and ethanol organosolv lignin from miscanthus. Polym. Degrad. Stab. 94, 16321638. doi:10.1016/j.polymdegradstab.2009.07.007

Hämäläinen, V., Grönroos, T., Suonpää, A., Heikkilä, M.W., Romein, B., Ihalainen, P., Malandra, S., Birikh, K.R., 2018. Enzymatic Processes to Unlock the Lignin Value . Front. Bioeng. Biotechnol. . 
medium pressure UV in swimming pool water. Sci. Total Environ. 443, 850-856. doi:10.1016/j.scitotenv.2012.11.064

Kang, X., Sun, Y., Li, L., Kong, X., Yuan, Z., 2018. Improving methane production from anaerobic digestion of Pennisetum Hybrid by alkaline pretreatment. Bioresour. Technol. 255, 205-212. doi:10.1016/j.biortech.2017.12.001

Kansal, S.K., Singh, M., Sud, D., 2008. Studies on TiO2/ZnO photocatalysed degradation of lignin. J. Hazard. Mater. 153, 412-417. doi:10.1016/j.jhazmat.2007.08.091

Kärkäs, M.D., Matsuura, B.S., Monos, T.M., Magallanes, G., Stephenson, C.R.J., 2016. Transition-metal catalyzed valorization of lignin: the key to a sustainable carbon-neutral future. Org. Biomol. Chem. 14, 1853-1914. doi:10.1039/C5OB02212F

Khoshnevisan, B., Tsapekos, P., Alvarado-Morales, M., Angelidaki, I., 2018. Process performance and modelling of anaerobic digestion using source-sorted organic household waste. Bioresour. Technol. 247, 486-495. doi:10.1016/j.biortech.2017.09.122

Klare, M., Scheen, J., Vogelsang, K., Jacobs, H., Broekaert, J.A.C., 2000. Degradation of short-chain alkyland alkanolamines by TiO2- and Pt/TiO2-assisted photocatalysis. Chemosphere 41, 353-362. doi:10.1016/S0045-6535(99)00447-6

Lee, H. V., Hamid, S.B.A., Zain, S.K., 2014. Conversion of Lignocellulosic Biomass to Nanocellulose: Structure and Chemical Process. Sci. World J. 2014, 1-20. doi:10.1155/2014/631013

Li, H., Lei, Z., Liu, C., Zhang, Z., Lu, B., 2015. Photocatalytic degradation of lignin on synthesized Ag$\mathrm{AgCl} / \mathrm{ZnO}$ nanorods under solar light and preliminary trials for methane fermentation. Bioresour. Technol. 175, 494-501. doi:10.1016/j.biortech.2014.10.143

Lux, 2014. Finding untapped value: converting lignin to higher value chemicals. Available at https://members.luxresearchinc.com/research/report/14807.

Ma, Y.-S., Chang, C.-N., Chiang, Y.-P., Sung, H.-F., Chao, A.C., 2008. Photocatalytic degradation of lignin 
using Pt/TiO2 as the catalyst. Chemosphere 71, 998-1004. doi:10.1016/j.chemosphere.2007.10.061

652

653

654

655

656

657

658

659

660

661

662

663

664

665

666

667

668

669

670

671

672

673

674

Machado, A.E.H., Furuyama, A.M., Falone, S.Z., Ruggiero, R., Perez, D.D.S., Castellan, A., 2000. Photocatalytic degradation of lignin and lignin models, using titanium dioxide: the role of the hydroxyl radical. Chemosphere 40, 115-124. doi:10.1016/S0045-6535(99)00269-6

Mainka, H., Hilfert, L., Busse, S., Edelmann, F., Haak, E., Herrmann, A.S., 2015. Characterization of the major reactions during conversion of lignin to carbon fiber. J. Mater. Res. Technol. 4, 377-391. doi:10.1016/j.jmrt.2015.04.005

Menon, V., Rao, M., 2012. Trends in bioconversion of lignocellulose: Biofuels, platform chemicals \& biorefinery concept. Prog. Energy Combust. Sci. doi:10.1016/j.pecs.2012.02.002

Moodley, P., Kana, E.B.G., 2017. Microwave-assisted inorganic salt pretreatment of sugarcane leaf waste: Effect on physiochemical structure and enzymatic saccharification. Bioresour. Technol. 235, 35-42. doi:10.1016/j.biortech.2017.03.031

Mou, H., Li, B., Fardim, P., 2014. Pretreatment of corn stover with the modified hydrotropic method to enhance enzymatic hydrolysis. Energy and Fuels 28, 4288-4293. doi:10.1021/ef5001634

Nair, V., Dhar, P., Vinu, R., 2016. Production of phenolics via photocatalysis of ball milled ligninTiO2mixtures in aqueous suspension. RSC Adv. 6, 18204-18216. doi:10.1039/c5ra25954a

Nelson, M.L., O’Connor, R.T., 1964. Relation of certain infrared bands to cellulose crystallinity and crystal lattice type. Part II. A new infrared ratio for estimation of crystallinity in celluloses I and II. J. Appl. Polym. Sci. 8, 1325-1341. doi:10.1002/app.1964.070080323

Pan, M., Gan, X., Mei, C., Liang, Y., 2017. Structural analysis and transformation of biosilica during lignocellulose fractionation of rice straw. J. Mol. Struct. 1127, 575-582. doi:10.1016/j.molstruc.2016.08.002

Pérez, J., Muñoz-Dorado, J., de la Rubia, T., Martínez, J., 2002. Biodegradation and biological treatments of cellulose, hemicellulose and lignin: an overview. Int. Microbiol. 5, 53-63. doi:10.1007/s10123-002- 
676 677 678 679 680 681 682 683 684 685 686 687 688 689 690 691 692 693 694 695 696 697

Pineda, A., Lee, A.F., 2016. Heterogeneously catalyzed lignin depolymerization. Appl. Petrochemical Res. 6, 243-256. doi:10.1007/s13203-016-0157-y

Prado, R., Erdocia, X., Labidi, J., 2013. Effect of the photocatalytic activity of TiO2 on lignin depolymerization. Chemosphere 91, 1355-1361. doi:10.1016/j.chemosphere.2013.02.008

Rauf, M.A., Ashraf, S.S., 2009. Fundamental principles and application of heterogeneous photocatalytic degradation of dyes in solution. Chem. Eng. J. 151, 10-18. doi:10.1016/j.cej.2009.02.026

Ren, H., Hou, Z., Han, X., Zhou, R., 2017. Highly reductive radical CO 2 - deriving from a system with SO 4 - and formate anion: Implication for reduction of $\mathrm{Cr}(\mathrm{VI})$ from wastewater. Chem. Eng. J. 309, 638645. doi:10.1016/j.cej.2016.10.071

Rosso, J.A., Bertolotti, S.G., Braun, A.M., Mártire, D.O., Gonzalez, M.C., 2001. Reactions of carbon dioxide radical anion with substituted benzenes. J. Phys. Org. Chem. 14, 300-309. doi:10.1002/poc.365

Segal, L., Creely, J.J., Martin Jr, A.E., Conrad, C.M., 1959. An empirical method for estimating the degree of crystallinity of native cellulose using the X-ray diffractometer. Text. Res. J. 29, 786-794.

Smolarski, N., 2012. High-value opportunities for lignin: unlocking its potential. Frost \& Sullivan 1.

Sun, Z., Fridrich, B., de Santi, A., Elangovan, S., Barta, K., 2018. Bright Side of Lignin Depolymerization: Toward New Platform Chemicals. Chem. Rev. 118, 614-678. doi:10.1021/acs.chemrev.7b00588

Sunthornvarabhas, J., Liengprayoon, S., Suwonsichon, T., 2017. Antimicrobial kinetic activities of lignin from sugarcane bagasse for textile product. Ind. Crops Prod. 109, 857-861. doi:10.1016/j.indcrop.2017.09.059

Todres, Z.V., 2009. Ion-radical organic chemistry: principles and applications, Chemistry \& biodiversity. CRC Press.

Tsapekos, P., Alvarado-Morales, M., Boscaro, D., Mazarji, M., Sartori, L., Angelidaki, I., 2018. TiO 2 - 
$\mathrm{AgCl}$ Based Nanoparticles for Photocatalytic Production of Phenolic Compounds from Lignocellulosic Residues. Energy \& Fuels 32, 6813-6822. doi:10.1021/acs.energyfuels.8b00572

Tsapekos, P., Kougias, P.G., Vasileiou, S.A., Lyberatos, G., Angelidaki, I., 2017. Effect of micro-aeration and inoculum type on the biodegradation of lignocellulosic substrate. Bioresour. Technol. 225, 246253. doi:10.1016/j.biortech.2016.11.081

Wang, M., Ma, J., Liu, H., Luo, N., Zhao, Z., Wang, F., 2018. Sustainable Productions of Organic Acids and Their Derivatives from Biomass via Selective Oxidative Cleavage of C-C Bond. ACS Catal. 8, 21292165. doi:10.1021/acscatal.7b03790

Zhang, J., Cai, Y., Lu, G., Cai, C., 2016. Facile and selective hydrogenolysis of $\beta$-O-4 linkages in lignin catalyzed by Pd-Ni bimetallic nanoparticles supported on ZrO2. Green Chem. 18, 6229-6235. doi:10.1039/C6GC02265K

Zoschke, K., Börnick, H., Worch, E., 2014. Vacuum-UV radiation at $185 \mathrm{~nm}$ in water treatment - A review. Water Res. 52, 131-145. doi:10.1016/j.watres.2013.12.034 
713 Table 1. Experimental ranges and levels of independent variables.

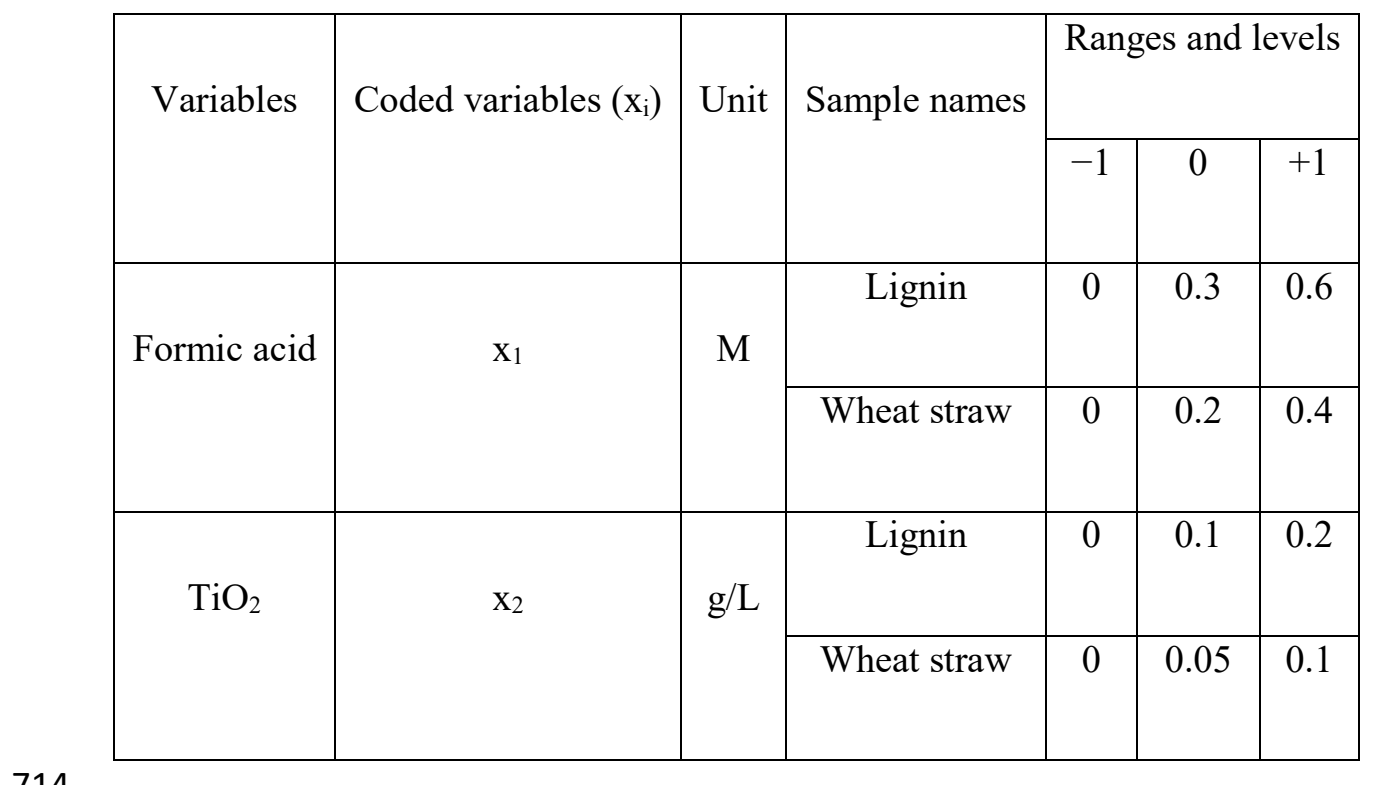

714

715 Table 2. fCCD design matrix for two variables with observed values for lignin and wheat straw samples.

\begin{tabular}{|c|c|c|c|c|c|}
\hline \multirow{2}{*}{ Run order } & \multicolumn{2}{|l|}{ Coded values } & Lignin & \multicolumn{2}{l|}{ Wheat Straw } \\
\cline { 2 - 6 } & $\mathrm{x}_{1}$ & $\mathrm{x}_{2}$ & Exp. TPC (\%) & Exp. TPC (\%) & Exp. sCOD (\%) \\
\hline 1 & +1 & -1 & $11.68 \pm 2.70$ & $76.33 \pm 1.69$ & $14.56 \pm 6.32$ \\
\hline 2 & +1 & 0 & $33.30 \pm 2.53$ & $66.47 \pm 0.19$ & $25.85 \pm 5.89$ \\
\hline 3 & +1 & +1 & $48.56 \pm 6.95$ & $62.91 \pm 3.00$ & $19.66 \pm 5.41$ \\
\hline 4 & 0 & -1 & $41.41 \pm 2.66$ & $68.94 \pm 2.57$ & $34.88 \pm 15.04$ \\
\hline 5 & 0 & +1 & $59.51 \pm 2.79$ & $70.92 \pm 0.52$ & $32.00 \pm 10.18$ \\
\hline 6 & 0 & 0 & $53.56 \pm 0.93$ & $72.12 \pm 4.59$ & $63.00 \pm 5.17$ \\
\hline & & & & & \\
\hline
\end{tabular}




\begin{tabular}{|c|c|c|c|c|c|}
\hline 7 & 0 & 0 & $53.00 \pm 0.91$ & $70.00 \pm 3.67$ & $60.00 \pm 4.89$ \\
\hline 8 & -1 & +1 & $-23.90 \pm 1.84$ & $19.89 \pm 3.06$ & $97.08 \pm 8.11$ \\
\hline 9 & -1 & 0 & $-6.16 \pm 1.85$ & $21.07 \pm 0.66$ & $100.00 \pm 9.98$ \\
\hline 10 & -1 & -1 & $3.18 \pm 0.80$ & $13.92 \pm 1.49$ & $95.00 \pm 12.84$ \\
\hline
\end{tabular}

Table 3. Major products obtained at the optimized conditions for in the solution phase of lignin and wheat straw sample by GC/MS.

\begin{tabular}{|l|l|l|l|l|}
\hline Peak & $\begin{array}{l}\text { Identified } \\
\text { No. }\end{array}$ & $\begin{array}{l}\text { Retention time } \\
(\mathrm{min})\end{array}$ & $\begin{array}{l}\text { Molecular weight } \\
(\mathrm{g} / \mathrm{mol})\end{array}$ & $\mathrm{m} / \mathrm{z}$ \\
\hline 1 & Guaiacol & $12.80 \mathrm{~min}$ & 124.14 & $124,109,95,81,65,53$ \\
\hline 2 & Isophthalaldehyde & $12.86 \mathrm{~min}$ & 134.13 & $134,105,77,51$ \\
\hline 3 & 2 -ethylphenol & $14.95 \mathrm{~min}$ & 122.17 & $122,107,91,77,51$ \\
\hline 4 & Phenol & $15.03 \mathrm{~min}$ & 94 & $94,66,55$ \\
\hline 5 & Vanillin & $19.30 \mathrm{~min}$ & 152.15 & $151,137,109,81,53$ \\
\hline 6 & 3 -methylindole & $19.55 \mathrm{~min}$ & 131.17 & $130,103,89,77,65$ \\
\hline 7 & 1 -naphthalenol & $22.88 \mathrm{~min}$ & 144.17 & $144,115,89,72,63$ \\
\hline 8 & Phthalimide & $22.96 \mathrm{~min}$ & 147.13 & $147,119,104,90,76,50$ \\
\hline 9 & 3 -phenyl furan & $23.39 \min$ & 144.17 & $144,115,89,72,63$ \\
\hline
\end{tabular}

Table 4. Elemental analysis of untreated and treated solid wheat straw's fiber at the optimized conditions.

\begin{tabular}{|c|c|c|c|c|}
\hline \multirow{2}{*}{ samples } & \multicolumn{4}{|c|}{ Elemental content (wt \%) } \\
\cline { 2 - 5 } & $\mathrm{C}$ & $\mathrm{H}$ & $\mathrm{N}$ & $\mathrm{O}$ \\
\hline Untreated wheat straw & $44.05 \pm 0.54$ & $6.66 \pm 4.24$ & $0.57 \pm 0.00$ & $48.72 \pm 3.55$ \\
\hline Treated wheat straw & $44.91 \pm 0.30$ & $7.00 \pm 0.67$ & $0.46 \pm 0.04$ & $47.63 \pm 0.07$ \\
\hline
\end{tabular}




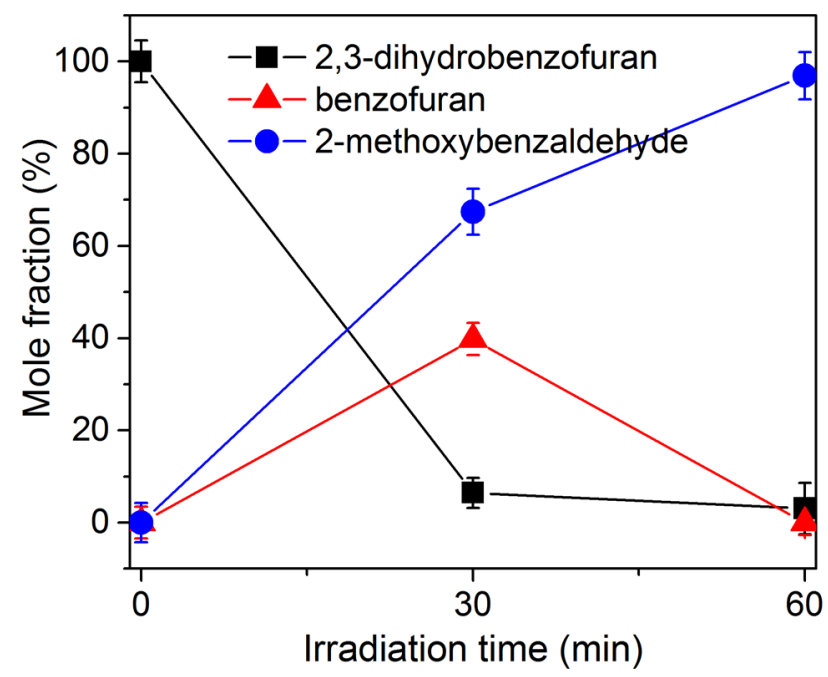

724 Fig. 1. Mole fraction profiles of 2,3-dihydrobenzofuran oxidation and its obtained products as a function of 725 time. Conditions: 2,3-dihydrobenzofuran loading $0.2 \mathrm{~g} / \mathrm{L}$; formic acid concentration $0.25 \mathrm{M}$; $\mathrm{TiO}_{2}$ dosage 0.1 $726 \mathrm{~g} / \mathrm{L}$; final volume $100 \mathrm{~mL}$; saturated with air.

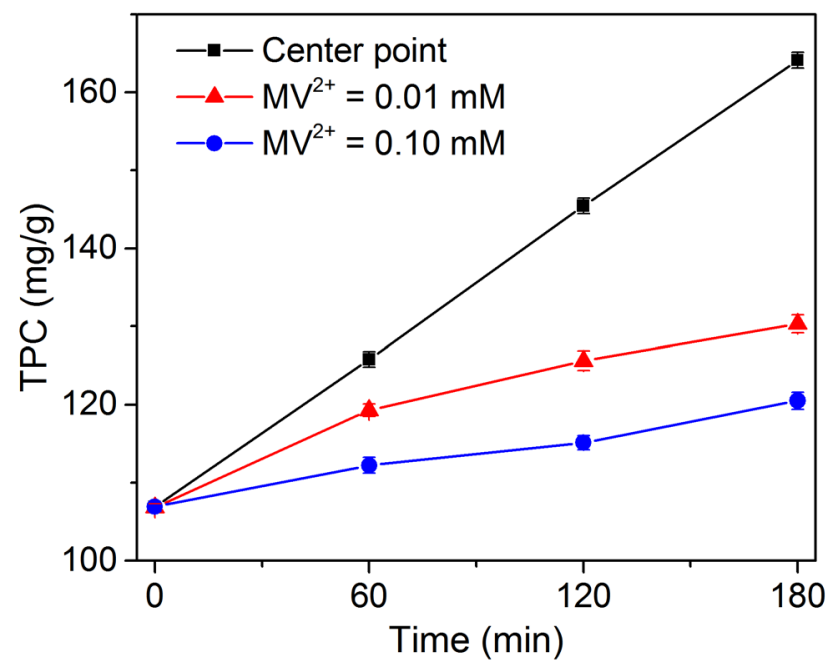

728 Fig. 2. TPC concentration $(\mathrm{mg} / \mathrm{g})$ as a function of time with the addition of different methyl viologen $\left(\mathrm{MV}^{2+}\right)$ 729 concentration at center point (experiments 6-7). Fixed experimental conditions: lignin loading $0.2 \mathrm{~g} / \mathrm{L}$; final 730 volume $100 \mathrm{~mL}$; saturated with air. 


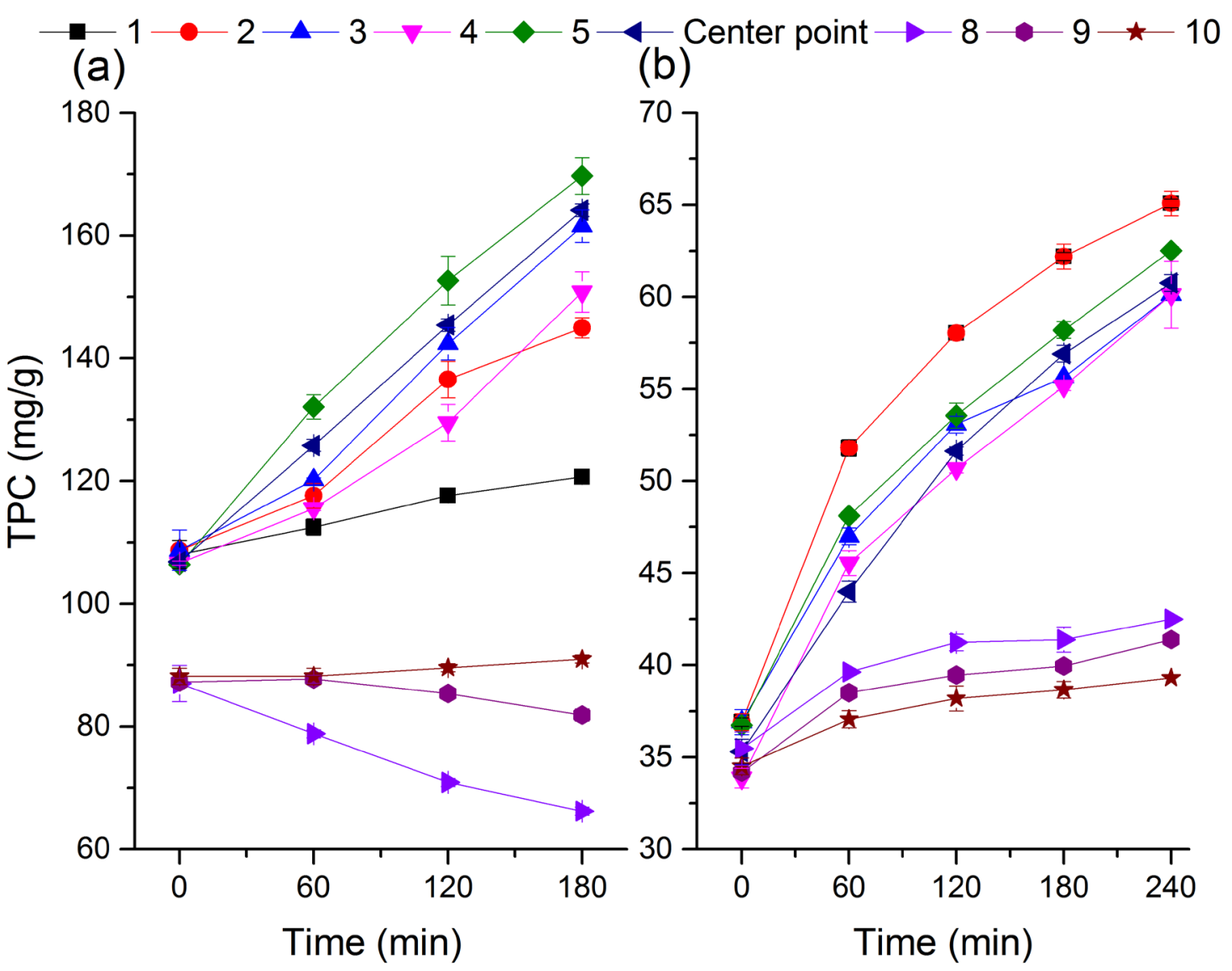

Fig. 3. TPC concentration $(\mathrm{mg} / \mathrm{g})$ as a function of time under different conditions according to the fCCD for a) lignin and b) wheat straw center point corresponds to the average of experiments 6-7. Fixed experimental conditions: lignin loading $0.2 \mathrm{~g} / \mathrm{L}$; wheat straw loading $1 \mathrm{~g} / \mathrm{L}$; final volume $100 \mathrm{~mL}$; saturated with air.
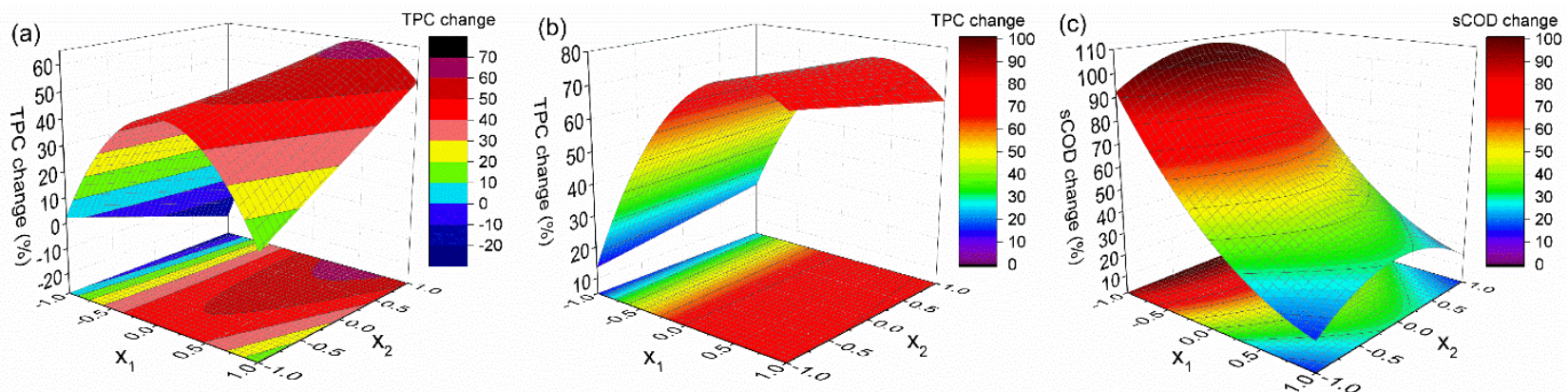

Fig. 4. Surface plots of a) TPC $\%$ change as a function of formic acid concertation $\left(\mathrm{x}_{1}\right)$ and $\mathrm{TiO}_{2}$ dosage $\left(\mathrm{x}_{2}\right)$ at irradiation time of 180 min for lignin, and surface plots of b) TPC \% change, and c) sCOD \% change as a function of formic acid concertation $\left(\mathrm{x}_{1}\right)$ and $\mathrm{TiO}_{2}$ dosage $\left(\mathrm{x}_{2}\right)$ at irradiation time of 240 min for wheat straw. [Fixed experimental conditions: lignin loading $0.2 \mathrm{~g} / \mathrm{L}$; wheat straw loading $1 \mathrm{~g} / \mathrm{L}$; final volume $100 \mathrm{~mL}$; saturated with air]. 


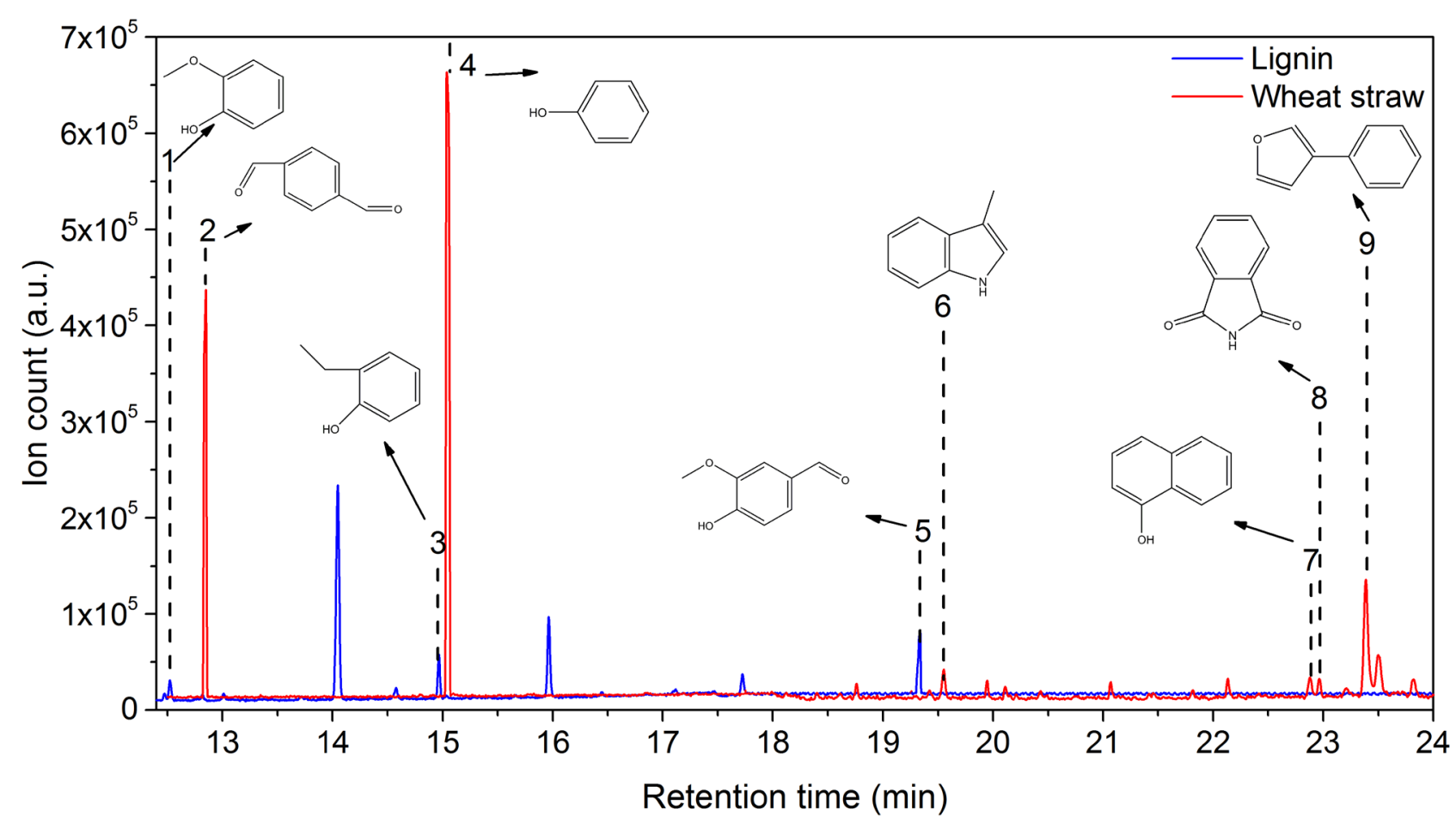

Fig. 5. GC/MS total ion chromatograms of phenolics obtained from photocatalysis of lignin and wheat straw

744 at the optimized conditions (for lignin: formic acid concentration $=0.4 \mathrm{M}\left(\mathrm{x}_{1}=+0.33\right)$ and $\mathrm{TiO}_{2}$ dosage $=0.2$ $745 \mathrm{~g} / \mathrm{L}\left(\mathrm{x}_{2}=+1\right)$; for wheat straw: $0.35 \mathrm{M}$ formic acid $\left(\mathrm{x}_{1}=+0.75\right)$ and photocatalyst-free condition $\left.\left(\mathrm{x}_{2}=-1\right)\right)$.

746 [Fixed experimental conditions: lignin loading $0.2 \mathrm{~g} / \mathrm{L}$; wheat straw loading $1 \mathrm{~g} / \mathrm{L}$; final volume $100 \mathrm{~mL}$;

747 saturated with air]. The peaks correspond to 1) guaiacol, 2) isophthalaldehyde, 3) 2-ethylphenol, 4) phenol, 748 5) vanillin, 6) 3-methylindole, 7) 1-naphthalenol, 8) phthalimide, 9) 3-phenyl furan. 

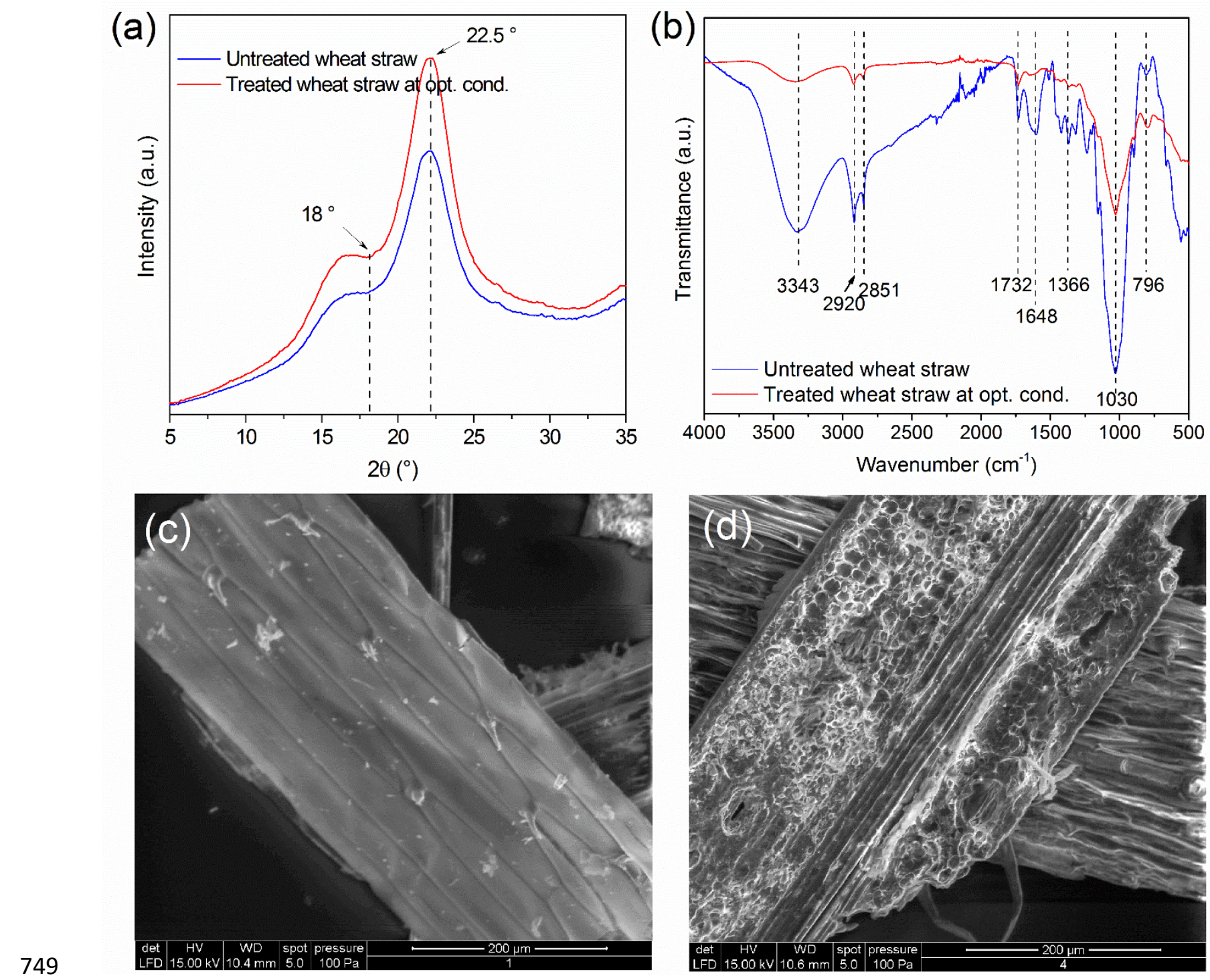

750 Fig. 6. (a) XRD and (b) FTIR spectra of wheat straw sample before and after pretreatment, (c, d) SEM

751 images of (c) untreated wheat straw and (d) treated wheat straw at the optimized conditions. 


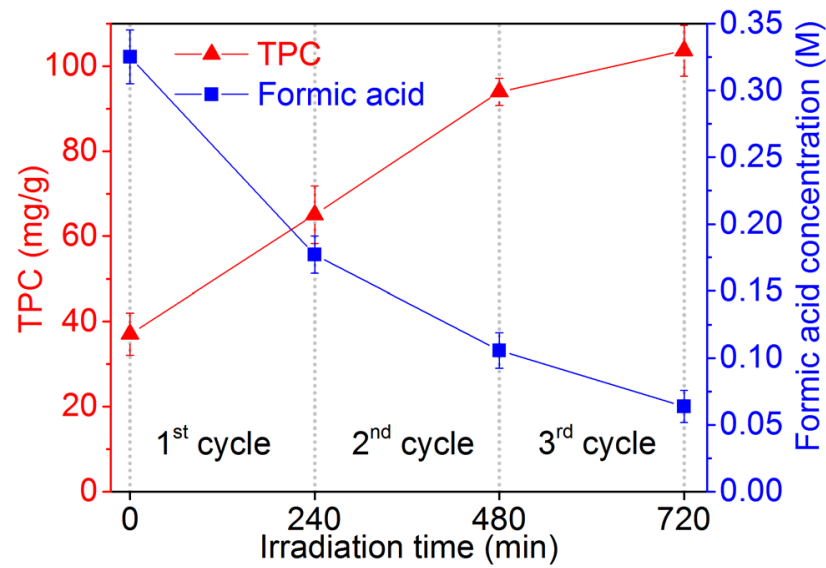

754 Fig. 7. TPC and formic acid concentration during three consecutive cycles for wheat straw sample at the 755 optimized conditions with $0.35 \mathrm{M}$ formic acid $\left(\mathrm{x}_{1}=+0.75\right)$ and photocatalyst-free condition $\left(\mathrm{x}_{2}=-1\right)$. [Fixed 756 experimental conditions: wheat straw loading $1 \mathrm{~g} / \mathrm{L}$; final volume $100 \mathrm{~mL}$; saturated with air].

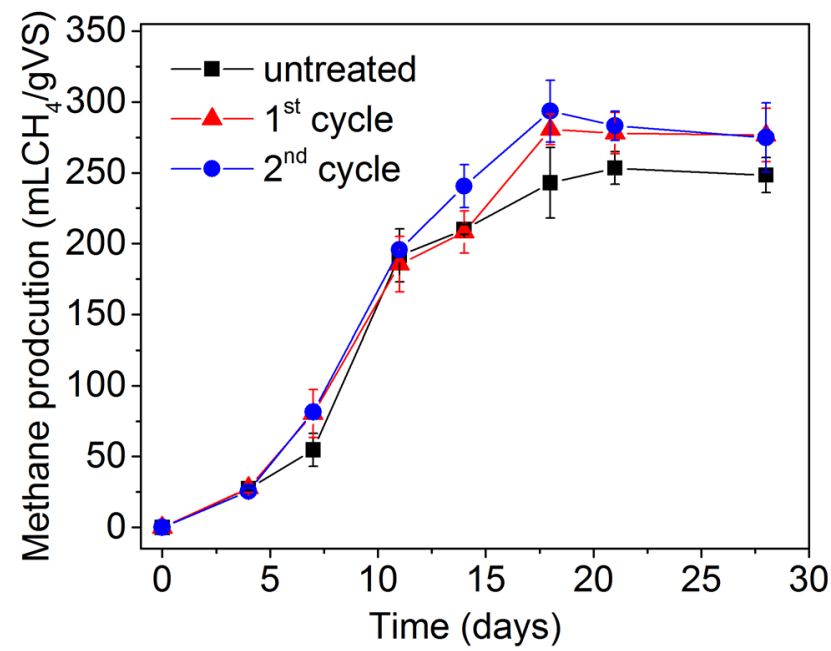

758 Fig. 8. BMP assay of untreated wheat straw along with $1^{\text {st }}$ cycle and $2^{\text {nd }}$ cycle pretreated fibers. 